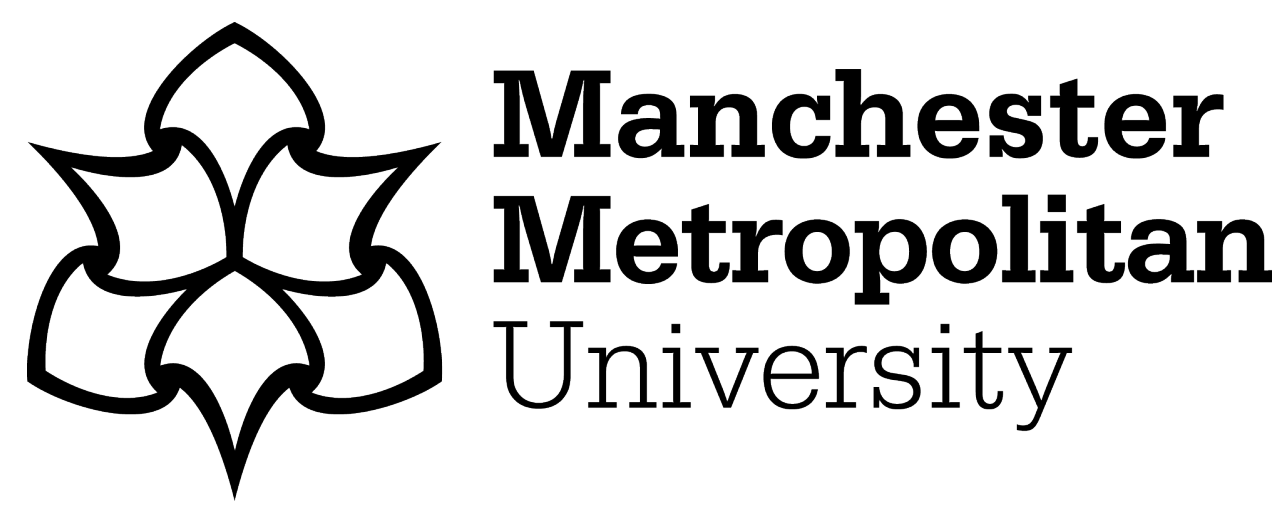

Boras, E, Slevin, M ORCID logoORCID: https://orcid.org/0000-0003-37674861, Alexander, MY, Aljohi, A, Gilmore, W, Ashworth, J ORCID logoORCID: https://orcid.org/0000-0001-7045-7899, Krupinski, J ORCID logoORCID: https://orcid.org/0000-0002-5136-8898, Potempa, LA, Al Abdulkareem, I, Elobeid, A and Matou-Nasri, S (2014) Monomeric C-reactive protein and Notch-3 co-operatively increase angiogenesis through PI3K signalling pathway. Cytokine, 69 (2). pp. 165-179. ISSN 1096-0023

Downloaded from: https://e-space.mmu.ac.uk/206/

Version: Accepted Version

Publisher: Elsevier

DOI: https://doi.org/10.1016/j.cyto.2014.05.027

Usage rights: Creative Commons: Attribution-Noncommercial-No Derivative Works 4.0

Please cite the published version 


\section{Monomeric C-reactive protein and Notch-3 co-operatively increase angiogenesis through PI3K signalling pathway}

Emhamed Boras ${ }^{1}$, Mark Slevin ${ }^{1}$, M Yvonne Alexander ${ }^{1,2}$, William Gilmore ${ }^{1}$, Jason Ashworth ${ }^{1}$, Jerzy Krupinski ${ }^{3}$, Lawrence A Potempa ${ }^{4}$, Ibrahim Al Abdulkareem ${ }^{5}$, Sabine Matou-Nasri ${ }^{{ }^{*}}$

${ }^{1}$ School of Healthcare Science, Cell and Molecular Biology Research Group, Healthcare Science Research Institute, Manchester Metropolitan University, Manchester M1 5GD, UK

${ }^{2}$ Institute of Cardiovascular Sciences, The University of Manchester, Manchester Academic Health Science Centre, Manchester M13 9NT, UK

${ }^{3}$ Hospital Universitari Mútua de Terrassa, Department of Neurology, Cerebrovascular Diseases Unit, Terrassa, Barcelona, Spain

${ }^{4}$ Roosevelt University College of Pharmacy, Schaumburg, Illinois, USA

${ }^{5}$ Medical Biotechnology Research Group, King Abdullah International Medical Research Center, National Guard Health Affairs, Riyadh 11426, Kingdom of Saudi Arabia

${ }^{*}$ Corresponding author:

Dr Sabine Matou-Nasri

Medical Biotechnology Research Laboratory

King Abdullah International Medical Research Center

National Guard Health Affairs

Riyadh

Kingdom of Saudi Arabia

Tel: +966-1-8016-590; Fax: +966-1-8016-662

E-mail: matouepnasrisa@ngha.med.sa 


\begin{abstract}
C-reactive protein (CRP) is the most acute-phase reactant serum protein of inflammation and a strong predictor of cardiovascular disease. Its expression is associated with atherosclerotic plaque instability and the formation of immature micro-vessels. We have previously shown that CRP up-regulates endothelial-derived Notch-3, a key receptor involved in vascular development, remodelling and maturation. In this study, we investigated the links between the bioactive monomeric CRP (mCRP) and Notch-3 signalling in angiogenesis. We used in vitro (cell counting, wound-healing and tubulogenesis assays) and in vivo (chorioallantoic membrane) angiogenic assays and Western blotting to study the angiogenic signalling pathways induced by mCRP and Notch-3 activator chimera protein (Notch-3/Fc). Our results showed an additive effect on angiogenesis of mCRP stimulatory effect combined with Notch-3/Fc promoting bovine aortic endothelial cell (BAEC) proliferation, migration, tube formation in Matrigel $^{\mathrm{TM}}$ with upregulation of phosho-Akt expression. The pharmacological blockade of PI3K/Akt survival pathway by LY294002 fully inhibited in vitro and in vivo angiogenesis induced by mCRP/Notch-3/Fc combination while blocking Notch signalling by $\gamma$-secretase inhibitor (DAPT) partially inhibited mCRP/Notch-3/Fc-induced angiogenesis. Using a BAEC vascular smooth muscle cell co-culture sprouting angiogenesis assay and transmission electron microscopy, we showed that activation of both mCRP and Notch-3 signalling induced the formation of thicker sprouts which were shown later by Western blotting to be associated with an up-regulation of Ncadherin expression and a down-regulation of VE-cadherin expression. Thus, mCRP combined with Notch-3 activator promote angiogenesis through the PI3K/Akt pathway and their therapeutic combination has potential to promote and stabilize vessel formation whilst reducing the risk of haemorrhage from unstable plaques.
\end{abstract}


Key words C-reactive protein, Notch, angiogenesis, PI3K/Akt pathway, $\gamma$-secretase 


\section{Introduction}

Deregulated angiogenesis is a key hallmark of vascular pathological conditions such as atherosclerotic plaque development, myocardial infarction and tumour growth [1]. Restoring perfusion to ischemic organs or limbs is a goal of therapeutic angiogenesis, while success with anti-angiogenic therapy has been a target for treatment of tumours. However, in both cases, there has been limited success to date, due to lack of a full understanding of the complex mechanisms underlying angiogenesis and vascular remodelling.

It has been reported that monomeric $\mathrm{C}$-reactive protein (mCRP) may be linked with plaque instability at the carotid bifurcation, thus contributing to haemorrhage [2]. We have previously detected mCRP expression in the adventitia and intimal neovessels from complicated regions of unstable carotid plaques [3] and of note, the formation of immature blood vessels, associated with ischemic stroke, has also been linked with over-expression of mCRP [4]. Furthermore, we have demonstrated in vitro and in vivo pro-angiogenic effects of mCRP via the ERK/MAPK pathway in association with a concomitant increase of Notch-3 gene expression [5], highlighting possible crosstalk between inflammatory cytokines and transcription factors essential for angiogenesis. Thus, the aim of this study was to specifically assess whether mCRP and Notch-3 signalling act together in a cooperative manner during angiogenesis and to establish the signalling pathways that link their coordination.

Mainly produced by the liver under interleukin- 6 stimulation, CRP is composed of five identical non-covalently associated non-glycosylated globular proteins of 23-kDa subunits arranged symmetrically around a pore $[6,7]$. The pro-bioactive component of the pentameric CRP (pCRP) is mainly due to its monomeric form, mCRP which appears from pCRP dissociation by its 
contact to the plasma membrane of apoptotic cells or activated platelets in atherosclerotic plaques $[8,9]$ or under drastic conditions (low $\mathrm{pH}$, absence of calcium, increased temperature and urea chelation) [10]. It binds to the cells through its main Fc $\gamma$ receptors (i.e. CD16, CD32 and CD64) with differential affinity on different cell types [11, 12]. As a prognostic marker of the development and progression of vascular disease, CRP plays a pivotal role by exerting direct modulatory effects on vascular cell functions including inflammatory, angiogenic and thrombotic properties $[5,7,9]$.

The Notch receptor plays a central role in the main stages of blood vessel formation including blood vessel remodelling, stabilization and maturation $[13,14]$. Notch proteins (Notch-1, Notch2, Notch-3, Notch-4) are single transmembrane receptors whose signalling is initiated by the interaction of one of the five canonical membrane-bound ligands (Jagged1, Jagged2 and Deltalikes D111, D113, and D114) expressed on the surface of adjacent cells. This interaction leads to a proteolytic cleavage by $\gamma$-secretase complex that releases the Notch intracellular domain (NICD) in the cytoplasm, and subsequent translocation to the nucleus [15]. Inside the nucleus, NICD

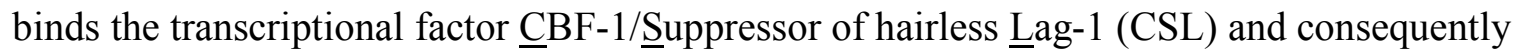
activates target gene expression resulting in cell fate decisions such as arterial/venous cell differentiation, proliferation, and survival/apoptosis during embryonic and postnatal development of many organs including the vasculature [15-17]. The function of Notch-3 as an essential component of vascular formation has been demonstrated in patients with stroke, where Notch-3 mutations cause the cerebral autosomal dominant arteriopathy known as CADASIL, a neurological disease characterized by vascular smooth muscle cell pathology and progressive brain ischemia due to an underlying arteriopathy $[18,19]$. In addition to the classical role of NICD activating downstream target genes, Notch receptor activation triggers signalling which 
cross-talks with phosphatidylinositol 3-kinase (PI3K)/Akt, extracellular signal-regulated kinase $(\mathrm{ERK}) /$ mitogen-activated protein kinase (MAPK), Src and Ras pathways [20, 21].

We hypothesize that, through the elevation of mCRP-induced Notch-3 gene expression level, mCRP and Notch-3 act in a co-operative manner in vascular endothelial cells, to exert a role in the remodelling and maturation of the vascular development; this study aims to investigate the endothelial angiogenic response and the common signalling pathways involved. The findings could have an impact on developing strategies to attenuate plaque rupture and to reduce the risk of haemorrhage in inflammatory vascular diseases. 


\section{Materials and Methods}

\subsection{Reagents}

Recombinant form of mCRP $(0.5 \mathrm{mg} / \mathrm{mL}$ in $25 \mathrm{mM} \mathrm{NaPBS}, \mathrm{pH} 7.4)$ was produced in the laboratory of Dr L.A. Potempa as previously described [22]. The mCRP solution contained an endotoxin concentration lower than $0.125 \mathrm{EU} / \mathrm{mL}$ and all cell culture medium was endotoxinfree. Notch-3/Fc chimeric protein was purchased from R\&D systems (Abingdon, UK). All secondary antibodies conjugated to horse-radish peroxidase were provided by DakoCytomation (Glostrup, Denmark). Rat tail collagen type I and growth factor-reduced Matrigel ${ }^{\mathrm{TM}}$ were purchased from Becton Dickinson (Bredford, MA). Pharmacological inhibitors for PI3K pathway (LY294002) and for $\gamma$-secretase activity (DAPT) were provided by Santa Cruz biotechnology (Middlesex, UK). All other reagents and items were purchased from SigmaAldrich (Dorset, UK).

\subsection{Culture of bovine aortic endothelial cells and smooth muscle cells}

Bovine aortic endothelial cells (BAEC) were isolated as previously described [23] and seeded in $75-\mathrm{cm}^{2}$ flasks (Nunc, Fischer Scientific, Loughborough, UK) pre-coated with $0.1 \%$ gelatine and cultured in Dulbecco's Modified Eagle Medium (Lonza, Cambridge, UK) supplemented with 20\% heat-inactivated fetal bovine serum (FBS, Cambrex, Hertfordshire, UK), 2 mM glutamine and $1 \%$ antibiotics $(100 \mu \mathrm{g} / \mathrm{mL}$ streptomycin, $100 \mathrm{U} / \mathrm{mL}$ penicillin), defined as complete medium. Bovine aortic smooth muscle cells (BASMC) were supplied by Health Protection Agency Culture Collections (Public Health England, Salisbury, UK) and cultured in specialized medium for smooth muscle cells (Lonza, UK), supplemented with $6 \%$ serum and $1 \%$ antibiotics. Both cell types were incubated at $37^{\circ} \mathrm{C}$ in a saturated air humidity $/ 5 \% \mathrm{CO}_{2}$-incubator, passaged 
every 2-3 days, using enzymatic digestion with $0.05 \%$ trypsin / $0.02 \%$ EDTA and split at a ratio of 1:2 or 1:3. At confluence, EC and SMC were identified by their typical cobblestone morphology and "hill and valley" configuration, respectively. The cells were used throughout the study between passages 4 and 9 .

\subsection{RNA extraction and reverse transcriptase $(R T)$ - polymerase chain reaction (PCR)} Extraction of total RNA from BAEC was performed and used to monitor the mRNA expression of bovine Notch-3 (XM_003582382.1). Complementary DNA (cDNA) was produced from total RNA extracts in two steps as previously described [24]. Primer pairs (Invitrogen - Life technologies, Paisley, UK) were selected by software Primer3 and the sequences used were: 5' AGC CAC TGT GAG CAG GAG AT 3' (sense) and 5' TGG AGG ACA GGA GCA GAG AT 3' (anti-sense) for bovine Notch-3, corresponding to a 220 bp-length fragment. The genespecific primer pairs used for PCR were optimized for cycle number $(35$ cycles $)$ and $t_{m}\left(59^{\circ} \mathrm{C}\right)$. PCR products were analysed by $1.5 \%$ agarose gel electrophoresis. Bovine ribosomal protein S14 gene expression was used as an internal standard.

\subsection{Endothelial cell proliferation assay}

BAEC $\left(2 \times 10^{4}\right.$ cells/well) were seeded in complete medium in $24-$ well plates (Nunc). After $4 \mathrm{~h}$ incubation, the medium was replaced with serum-poor medium (SPM; medium supplemented with $2.5 \% \mathrm{FBS}$ ) with or without $5 \mu \mathrm{g} / \mathrm{mL} \mathrm{mCRP}$ and $\pm 20 \mathrm{ng} / \mathrm{mL}$ Notch $-3 / \mathrm{Fc}$, in the presence or absence of pharmacological inhibitors DAPT ( $\gamma$-secretase inhibitor; $10 \mu \mathrm{M})$ and LY294002 (PI3K/Akt pathway inhibitor; $10 \mu \mathrm{M}$ ). Each condition was performed in triplicate, with SPM or $0.05 \%$ dimethyl sulfoxide (DMSO)-treated cells used as negative controls. After $72 \mathrm{~h}$ incubation, 
the cells were detached in $250 \mu \mathrm{L}$ of $0.05 \%$ trypsin $/ 0.02 \%$ EDTA and then each cell suspension was diluted in $10 \mathrm{~mL}$ of isotonic solution prior to counting using a Beckman-Coulter counter (London, UK).

\subsection{Endothelial cell migration - wound recovery assay}

BAEC $\left(1.2 \times 10^{5}\right.$ cells/well) were seeded in complete medium on Thermanox ${ }^{\circledR}$ coverslips (Nunc) in 24-well plates. After reaching pre-confluence following incubation for $24 \mathrm{~h}$, each monolayer was wounded on two sides with a sterile razor blade, which gave the formation of two wound edges per coverslip with cell denuded areas. Dislodged cells were removed by washing with PBS without $\mathrm{Ca}^{2+} / \mathrm{Mg}^{2+}$. Then the coverslips were bathed in SPM with or without $5 \mu \mathrm{g} / \mathrm{mL}$ $\mathrm{mCRP} \pm 20 \mathrm{ng} / \mathrm{mL}$ Notch-3/Fc in the presence or absence of $10 \mu \mathrm{M}$ DAPT $\pm 10 \mu \mathrm{M}$ LY294002. Each condition was performed in duplicate and SPM or 0.05\% DMSO-treated cells were used as negative controls. After $24 \mathrm{~h}$ incubation, cells were washed with PBS, fixed with methanol and stained with $0.1 \%$ methylene blue. Cell migration from the wound edge into the denuded area was quantified using Image J software (http://rsb.info.nih.gov/nih.image/).

\subsection{Endothelial tube formation assay in tri-dimensional Matrigel ${ }^{\mathrm{TM}}$ culture $^{\mathrm{a}}$}

BAEC $\left(1.5 \times 10^{6}\right.$ cells $\left./ \mathrm{mL}\right)$ were mixed in equal volume with growth factor-reduced Matrigel ${ }^{\mathrm{TM}}$ $(10 \mathrm{mg} / \mathrm{mL})$ with or without $5 \mu \mathrm{g} / \mathrm{mL} \mathrm{mCRP} \pm 20 \mathrm{ng} / \mathrm{mL}$ Notch-3/Fc in the presence or absence of $10 \mu \mathrm{M}$ DAPT $\pm 10 \mu \mathrm{M}$ LY294002. In 48-well plates (Nunc), each mixture was equally poured under a spot shape into two wells per experimental condition. After polymerization of the gel for $1 \mathrm{~h}$ at $37^{\circ} \mathrm{C}$, each spot of cells embedded in Matrigel ${ }^{\mathrm{TM}}$ was bathed in $500 \mu \mathrm{L}$ of complete medium. Each condition was performed in duplicate and complete medium or $0.05 \%$ DMSO- 
treated cells were used as negative controls. After $24 \mathrm{~h}$ incubation, some cells migrated, aligned to form tubes with the formation of closed areas lined by the tubes. The cells were fixed with $4 \%$ PFA for $15 \mathrm{~min}$ and the closed areas, used as a parameter for quantification of tubulogenesis [25], were counted in 5 random fields.

\subsection{Western blot analysis}

For the study of intracellular protein expression, BAEC $\left(10^{5}\right.$ cells/well $)$ were seeded in complete medium in a 24-well plate. After $48 \mathrm{~h}$ incubation, the medium was renewed with SPM for further $24 \mathrm{~h}$ incubation, and then $5 \mu \mathrm{g} / \mathrm{mL} \mathrm{mCRP} \pm 20 \mathrm{ng} / \mathrm{mL}$ Notch-3/Fc were added for $10 \mathrm{~min}$ stimulation at $37^{\circ} \mathrm{C}$. After fast washing in cold PBS, cells were lysed with $120 \mu \mathrm{L} /$ well of icecold radioimmunoprecipitation (RIPA) buffer ( $\mathrm{pH}$ 7.5) as previously described until the transfer of the proteins onto nitrocellulose filters [5]. For the study of adhesion molecule expression, cocultured BAEC/SMC ( $10^{5}$ cells/well $)$ were seeded on collagen gel in complete medium in a 24well plate. After $4 \mathrm{~h}$ incubation, the medium was replaced with SPM with or without $5 \mu \mathrm{g} / \mathrm{mL}$ $\mathrm{mCRP} \pm 20 \mathrm{ng} / \mathrm{mL}$ Notch-3/Fc. Each condition was performed in duplicate and complete medium or $0.05 \%$ DMSO-treated cells were used as negative controls. After 3 days of culture, the cells were washed with cold PBS and then lysed for $1 \mathrm{~h}$ on ice with $80 \mu \mathrm{L} /$ well of lysis buffer containing $50 \mathrm{mM}$ tris $\mathrm{HCl}(\mathrm{pH} 8.0), 150 \mathrm{mM} \mathrm{NaCl}, 1 \mathrm{mM}$ EDTA, $0.25 \%$ sodium deoxycholate, $1 \%$ Triton X-100 and $1 \mu \mathrm{M}$ leupeptin. After protein estimation using Bradford protein assay (Biorad, Munchen, Germany), $100 \mu \mathrm{g}$ of proteins were mixed with $2 \mathrm{X}$ Laemmli sample buffer then were separated by 10\% SDS-PAGE and electroblotted (Hoefer, Bucks, UK) onto nitrocellulose filters $(1 \mathrm{~h})$. Nitrocellulose filters were blocked for $1 \mathrm{~h}$ at room temperature in TBS-Tween (pH 7.4) containing 1\% BSA, and stained with the following primary antibodies 
diluted in the blocking buffer, overnight at $4{ }^{\circ} \mathrm{C}$ on a rotating shaker: goat polyclonal antibodies to total Akt (t-Akt, 1:1000), rabbit polyclonal antibodies to p-Akt (Thr308, 1:500) and mouse polyclonal antibody to $\beta$-tubulin from Santa Cruz Biotechnology, rabbit polyclonal antibodies to VE-cadherin (1:1000) from Upstate Biotechnology (Lake Placid, NY) and mouse monoclonal antibodies to N-cadherin (1:1000) from Novus Biologicals (Cambridge, UK). After washing (5x 10 min in TBS-Tween at room temperature) filters were stained with either rabbit anti-goat, goat anti-rabbit or rabbit anti-mouse horse-radish peroxidase-conjugated secondary antibodies diluted in TBS-Tween containing 5\% de-fatted milk $(1: 1000,1 \mathrm{~h}$, room temperature $)$ with continuous mixing. After a further 5 washes in TBS-Tween, proteins were visualized by ECL (Geneflow Ltd, Staffordshire, UK) chemiluminescent detection and the image captured by Syngene imaging system was analysed using GeneSnap software (Syngene, Cambridge, UK).

\subsection{Chick chorio-allantoic membrane (CAM) assay}

Fertilised Dekalb White hen's eggs (Henry Stewart Ltd, Louth, Lincolnshire, UK) were received at day 0 and incubated in a humidified egg incubator (R-COM, Powys, UK) for 6 days. After this incubation, the location of the embryo was checked using an egg candle, then the opposite side of the shell was chosen to punch a small hole, $3 \mathrm{~mL}$ of albumin were aspirated using a $25-\mathrm{G}$ hypodermic needle and a window was carefully created over embryonic blood vessels. Sterile Whatman filter papers with a $6 \mathrm{~mm}$ diameter hole in the centre were placed onto the CAM and the following $5 \mu \mathrm{L}$ treatments were administered via the middle of the hole: sterile PBS (control), $0.5 \mathrm{mg} \mathrm{mCRP}, 80 \mathrm{ng}$ Notch-3/Fc and the addition of $\mathrm{mCRP}$ to Notch-3/Fc in the presence or absence of $10 \mu \mathrm{M}$ LY294002 or $10 \mu \mathrm{M}$ DAPT. Each condition was performed in triplicate and complete medium or $0.05 \%$ DMSO-treated cells were used as negative controls. 
After 3 days of incubation, the vessels were photographed using a Leitz dissecting microscope at a magnification of $x 40$. Angiogenesis was quantified by measuring the vessel length, the vessel area using Image $\mathrm{J}$ software and by counting the vessel branch-points per $0.1 \mathrm{~mm}^{2}$ density. The experiments were independently repeated five times for each condition.

\subsection{Tri-dimensional sprout formation assay: spheroids embedded in collagen gel}

BAEC/SMC co-culture spheroids were generated by mixing $125 \mu \mathrm{L}$ of $3 \times 10^{5} / \mathrm{ml}$ of BAEC added to $125 \mu \mathrm{L}$ of $3 \times 10^{5} / \mathrm{ml}$ of BASMC with $15 \mathrm{~mL}$ of $1.2 \%$ methylcellulose (4000 Cp viscosity). Then $150 \mu \mathrm{L}$ of the $15 \mathrm{~mL}$ mixture were distributed in each well of 96-well Greiner® plates. After 2 days of incubation at $37^{\circ} \mathrm{C}$ and for each experimental condition, 48 well-formed spheroids were collected, centrifuged at $400 \mathrm{~g}$ for $3 \mathrm{~min}$ and re-suspended in $250 \mu \mathrm{L}$ of methylcellulose with or without either $5 \mu \mathrm{g} / \mathrm{mL} \mathrm{mCRP}, 20 \mathrm{ng} / \mathrm{ml}$ Notch-3/Fc or both. The collagen solution $(250 \mu \mathrm{L}$ of $2 \mathrm{mg} / \mathrm{mL})$ which had been previously neutralized with $0.1 \mathrm{~N} \mathrm{NaOH}$ was added to the spheroid mixture. Each collagen-spheroid mixture was equally distributed in a 24-well plate, in duplicate for each condition. After 2 days of incubation, sprouting occurred from the spheroid core and to measure the length of the sprouts, the spheroids were fixed with 4\% PFA for $15 \mathrm{~min}$. The sprout length was estimated using the software Image $\mathrm{J}$ from 5 spheroids with a similar sized core.

\subsection{Transmission electronic microscopy}

The spheroids were fixed overnight with $2 \%$ formaldehyde $/ 2 \%$ glutaraldehyde in $0.1 \mathrm{M}$ cacodylate buffer $(\mathrm{pH} 7.2)$ and post-fixed with reduced osmium $\left(1 \% \mathrm{OsO}_{4}\right.$ and $\left.1.5 \% \mathrm{~K}_{4} \mathrm{Fe}(\mathrm{CN})_{6}\right)$ for $1 \mathrm{~h}$, then with $1 \%$ tannic acid in $0.1 \mathrm{M}$ cacodylate buffer for $1 \mathrm{~h}$ and finally with $1 \%$ uranyl 
acetate in water. The spheroids were dehydrated in a battery of alcohols, infiltrated with TAAB $\mathrm{LV}$ resin and polymerized for $24 \mathrm{~h}$ at $60^{\circ} \mathrm{C}$. Ultrathin sections $(70 \mathrm{~nm})$ were cut with a Leica Ultracut S ultramicrotome and placed on formvar/carbon coated slot grids. The grids were observed in a Tecnai 12 Biotwin transmission electronic microscopy at $80 \mathrm{kV}$.

\subsection{Statistics}

Results were expressed as mean \pm standard deviation (SD). Experimental points were performed with a minimum of three independent experiments. An unpaired Student's t-test was used for comparison of two groups. A value of $\mathrm{P}<0.05$ was considered significant. 


\section{Results}

\section{1. mCRP and Notch-3/Fc activation increase EC proliferation, migration and tube}

\section{formation}

Using RT-PCR, we confirmed that mCRP up-regulated Notch-3 gene expression in cultured bovine aortic endothelial cells (BAEC) (Figure 1A). After $24 \mathrm{~h}$ incubation, mCRP enhanced Notch-3 gene expression in a dose-dependent manner (Figure $1 \mathrm{~A}_{1}$ ). The half-maximum stimulation level of Notch-3 gene expression was achieved with as little as $5 \mu \mathrm{g} / \mathrm{mL} \mathrm{mCRP}$ (Figure $1 \mathrm{~A}_{2}$ ). Next, we treated the endothelial cells with $20 \mathrm{ng} / \mathrm{mL}$ of a Notch signalling activator chimera protein called Notch-3/Fc for $10 \mathrm{~min}$ (conditions fixed by pilot studies, data not shown). Western blot analysis demonstrated an increase in the release of Notch intracellular domain (NICD) fragments, indicative of activation of Notch receptor signalling by Notch-3/Fc (Figure $1 \mathrm{~B}_{1}$ ). Of note, Notch-3/Fc induced activation of Notch signalling was prevented using 10 $\mu \mathrm{M}$ of $\gamma$-secretase inhibitor DAPT, which abolished the generation of NICD fragments (Figure $\left.1 \mathrm{~B}_{2}\right)$

After 3 days of incubation, both mCRP and Notch-3/Fc significantly increased the endothelial cell number by $1.31-$ fold $(p=0.007)$ and 1.43 -fold $(p=0.003)$ respectively, as compared to the control untreated cells (Figure 2A). A combination treatment of mCRP with Notch-3/Fc showed additive effects (1.64-fold increase) as compared to the control cells, with a significant increase compared to either mCRP $(p=0.007)$ or to Notch-3/Fc alone $(p=0.018$, figure $2 \mathrm{~A})$.

After $24 \mathrm{~h}$ of incubation, both mCRP (Figure 2Bii) and Notch-3/Fc (Figure 2Biii) significantly increased the distance of migration by 1.23 -fold $(\mathrm{p}=0.002)$ and 1.35 -fold $(\mathrm{p}=0.03)$, respectively compared to the control cells (Figures $2 \mathrm{Bi}$ and $2 \mathrm{Bv}$ ). Their combination (Figure 2Biv) significantly increased the distance of migration by 1.38 -fold ( $\mathrm{p}=0.013$ ) compared to the 
control cells, with a significant increase compared to mCRP alone (Figure 2Bv). The number of migrated cells was significantly increased $(2.1$-fold, $p=0.04)$ by the combined factors, compared to the control or individual stimulation by either mCRP or Notch-3/Fc alone (Figure $2 \mathrm{Bv}$ ).

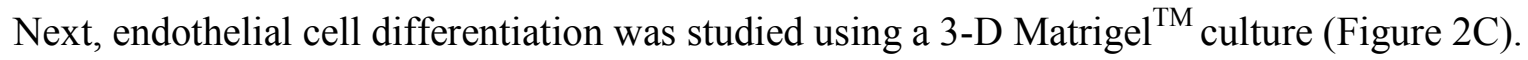
Within $24 \mathrm{~h}$ of incubation with respective treatments, activated cells migrated, aligned to form tubes organized in a capillary-like network. Compared to the control (Figure 2Ci), mCRP (Figure 2Cii) and Notch-3/Fc (Figure 2Ciii) significantly increased the mean of closed areas lined by the tubes by 1.98 -fold $(p=0.008)$ and by 2.10 -fold $(p=0.002)$ respectively (Figure $2 \mathrm{Cv}$ ). Moreover, the combined factors demonstrated an additive effect $(2.65$-fold, $p=0.0006$, Figure 2Civ) with a significant difference when compared to each stimulus alone (Figure 2Cv).

\section{2. mCRP and Notch-3/Fc enhance p-Akt expression}

Recently identified as Notch-3 downstream target cytoplasmic protein [21], we assessed the variation of the survival phospho-protein p-Akt expression level after endothelial cell treatment with Notch-3/Fc and mCRP as well, for 10 min incubation (optimal incubation time determined from pilot studies, data not shown). Untreated cells displayed a low basal expression of p-Akt (Figure 3A). Once stimulated by the addition of mCRP, an increase of p-Akt expression was detected, while Notch-3/Fc significantly enhanced p-Akt expression level by 2.2 -fold, compared to untreated cells (Figures $3 \mathrm{~A}$ and $3 \mathrm{~A}_{1}$ ). The combined treatment with mCRP and Notch-3/Fc was found to have an additive effect on p-Akt expression level showing a 3.7-fold increase compared to the basal level (Figure $3 \mathrm{~A}_{2}$ ), suggesting cross-talk with the PI3K/Akt survival pathway. 
To verify this theory, we treated the cells with DAPT $(10 \mu \mathrm{M})$, the pharmacological inhibitor of Notch signalling activation, and with LY294002 (10 $\mu \mathrm{M})$, the inhibitor of PI3K/Akt signalling prior to a 10 min mCRP and Notch-3/Fc cell stimulation (Figure 3B). From pilot studies, the concentration of the pharmacological drugs or DMSO (data not shown) used did not change the basal level of p-Akt expression, compared to untreated cells. DAPT inhibited Notch-3/Fcinduced p-Akt overexpression with an attenuation of the combined mCRP/Notch-3/Fc-induced p-Akt expression (Figure 3B). The addition of LY294002 inhibited phosphorylation of Akt by either single or combined stimulation (Figure 3B). Similar results were observed by the addition of the two inhibitors.

\subsection{LY294002 and DAPT attenuate mCRP and Notch-3 pro-angiogenic activities in vitro}

Using two pharmacological inhibitors of PI3K/Akt and of Notch signalling activation in all in vitro angiogenic assays (Figure 4), we demonstrate that the addition of LY294002 (10 $\mu \mathrm{M})$ prevents both mCRP- and Notch-induced cell proliferation (Figure 4A), compared to control. The addition of DAPT prevents Notch-3/Fc positive mitogenic effect but not mCRP effects. The addition of the two inhibitors LY294002 and DAPT gave similar results on cell proliferation to those observed with LY294002 alone (Figure 4A). Blocking PI3K signalling with LY294002 significantly decreased mCRP- and Notch-3/Fc-induced vascular cell migration (Figure 4B), while addition of DAPT inhibited Notch-3/Fc-induced cell migration but had no effect on mCRP-induced endothelial cell migration (Figure 4B). As in the case for cell proliferation, the addition of the combined inhibitors decreased mCRP- and Notch-3/Fc-induced endothelial cell migration in a similar manner to that produced by LY294002 alone (Figure 4B). In contrast, 
DAPT significantly inhibited both mCRP and Notch-induced tube formation whereas in the presence of LY294002 (alone or added to DAPT), no change in tubulogenesis was observed after mCRP or Notch treatment (Figure 4C). Of note, the positive effects on tube formation caused by combined mCRP/Notch-3/Fc treatment was retained even after addition of LY294002 or DAPT but the pro-angiogenic effect was abolished when the inhibitors were added together (Figure 4C).

\section{4. $\mathrm{mCRP}$ and Notch3/Fe promotes angiogenesis in vivo}

Monomeric CRP and Notch signalling activator chimera protein Notch-3/Fc were tested on 6day-old chick chorio-allantoic membranes, to assess the formation of neo-vessels over 3 dayincubation (Figure 5A). The neo-vessel formation was quantified by the mean of 3 scores: actual vessel number, vessel branch-point number and total vessel area. Compared to the PBS control (Figure 5Ai), mCRP $(0.5 \mathrm{mg} / 5 \mu \mathrm{l}$, Figure 5Aii) significantly increased both vessel number by 1.37 -fold $(\mathrm{p}=0.0034$, Figure 5B) and number of branch-points by 3.5 -fold $(\mathrm{p}=0.001$, Figure 5B). Notch-3/Fc ( $80 \mathrm{ng} / 5 \mu \mathrm{l}$, Figure 5Aiii) enhanced vessel number by 1.45 -fold $(\mathrm{p}=0.003$, Figure $5 B)$ and vessel branch-point number by 1.8 -fold $(p=0.018$, Figure $5 B)$. The combined effect of mCRP with Notch-3/Fc (Figure 5Aiv) increased both the vessel number, branch-points (Figure 5B), and the vessel area density by 3.15 -fold $(p=0.001$, Figure $5 C)$.

The formation of neo-blood vessels of the chorio-allantoic membrane induced by combined mCRP with Notch-3/Fc was inhibited by DAPT and more markedly inhibited by LY294002 (Figure 5D). Blocking Notch signalling using DAPT in cells with the combined treatment of mCRP and Notch-3/Fc resulted in a $40 \%$ decrease of the vessel number density (Figure 5D). The addition of LY294002 to combined mCRP/Notch-3/Fc treatment inhibited the angiogenic 
process by $80 \%$ (Figure 5D). However surprisingly, the combination of both inhibitors DAPT and LY294002 added to the combined mCRP and Notch-3/Fc treatment, prevented the strong anti-angiogenic response and decreased the vessel number density by only $25 \%$, when compared to the vascular network formed by the mCRP/Notch-3/Fc treatment in the absence of inhibitors (Figure 5D).

\section{5. mCRP with Notch-3/Fc enhance the thickness of sprouting angiogenesis via up- regulation of $\mathrm{N}$-cadherin expression and down-regulation of VE-cadherin in a EC/SMC co-culture}

In order to further investigate the effect of mCRP in Notch-induced maturation of new vessels, a sprouting angiogenesis assay was utilized to detect the tri-dimensional outgrowth of EC/SMC co-culture spheroids embedded in a collagen gel. Under the effect of each stimulatory agent, more cells migrated and aligned to form longer sprouts from the core of spheroids (Figure 6Aiiv). After $48 \mathrm{~h}$ of incubation and compared to control (Figure 6Ai), both mCRP (Figure 6Aii) and Notch-3/Fc (Figure 6Aiii) significantly increased the sprout length to the same extent (2-fold, $p<$ 0.05, Figure 6B). However, a distinction was observed in the vascular structure, with mCRPtreated cells showing a disconnected structure while treatment with Notch-3/Fc caused the cells to become more elongated and align closer to each other. Additive effects were observed by their combination inducing a significant increase in the sprout length by $2.75-$ fold $(p=0.001$, Figure 6B). Using transmission electronic microscopy (Figure 6C), ultra-structural sections of coculture EC/SMC spheroids untreated (Figure 6Ci) or treated with mCRP (Figure 6Cii), Notch3/Fc (Figure 6Ciii) and their combination (Figure 6Civ) showed the vascular cell organization 
into sprouts. The thin structure of the sprout induced by mCRP (with apparent disconnection) was explained by finer filopodia (indicated by arrows, Figure 6ii) of some cells which maintained the straightness of the vascular structure. Under Notch-3/Fc stimulation, closer interactions between the cells were observed. The effect of the combination mCRP with Notch3/Fc induced a better organization side by side between the vascular cells, which suggested a stabilization of the vascular sprout structure (Figure 6Civ).

To highlight the adhesive structural proteins that may be involved in mCRP and Notch-induced sprouting angiogenesis and vascular stability, we used Western blot analysis to detect VEcadherin and $\mathrm{N}$-cadherin in lysates of co-cultured vascular cells after 3-day incubation in collagen gel (Figure 6D). mCRP up-regulated VE-cadherin expression while Notch-3/Fc downregulated its expression, compared to the control untreated co-cultured vascular cells (Figure 6D). N-cadherin expression was up-regulated by both mCRP and Notch-3/Fc and its induction was stronger when mCRP was combined with Notch-3/Fc. In contrast, VE-cadherin expression was undetectable in the presence of both mCRP and Notch-3/Fc (Figure 6D). 


\section{Discussion}

In this study, we provide the first insight into the combined effects of monomeric C-reactive protein (mCRP) and Notch-3 signalling activator chimera protein (Notch-3/Fc) through the PI3K/Akt survival pathway, leading to increased angiogenesis. In addition, we showed that the Notch signalling activator Notch-3/Fc in combination with mCRP contributes to the enhancement of the thickness of vascular sprouts embedded in collagen gel, and is associated with a concomitant increase of $\mathrm{N}$-cadherin expression and a down-regulation of VE-cadherin protein expression. Thus, combined mCRP with Notch-3 might promote and stabilize vessel formation whilst reducing the risk of haemorrhage from immature blood vessels or unstable plaque in vascular diseases.

CRP is an important acute-phase reactant protein in patients and a strong predictor of cardiovascular disease. Associated with the contribution of inflammation to the pathogenesis of atherosclerosis, CRP expression has been correlated with unstable plaque in vascular diseases and an increased risk of haemorrhage [3]. Furthermore, its bioactive monomeric form (mCRP) has been shown to be abundantly expressed in immature micro-vessels located in peri-infarcted regions of patients with acute ischemic stroke [4]. Although Notch-3 receptor is widely known to be expressed mainly by mural cells and to contribute to blood vessel stability, we previously reported an up-regulation of Notch-3 gene expression by mCRP in cultured aortic endothelial cells [5].

Here, a purified and endotoxin-free mCRP solution, at the concentration of $5 \mu \mathrm{g} / \mathrm{mL}$ corresponding to the CRP plasma concentration of patients with high cardiovascular risk, has been used to successfully stimulate angiogenesis, as shown by increased endothelial cell 
proliferation, migration and tube formation. Previously, CRP biological activities have been subjected to many controversies because of the use of commercial CRP solutions containing contaminants such as endotoxin and sodium azide as causal agents of these effects [26]. In this study, we used an endotoxin-free and purified recombinant mCRP, demonstrated to be the bioactive form of the CRP [3, 4]. Many studies reported that CRP induces endothelial cell dysfunction including inhibition of cell proliferation, increased apoptosis, and reduced expression of eNOS; however, Taylor and her colleagues demonstrated that these effects were in fact caused by the contaminants present in the commercial CRP solution [26]. Using vascular cells isolated from thoracic aortas and the coronary circulation, Cirillo and his colleagues reported that a commercial endotoxin-free and purified CRP increased endothelial cell proliferation in a dose-dependent manner (from $20 \mu \mathrm{g} / \mathrm{mL}$ ) through ERK/MAPK pathway [27]. In support of these data, we directly report that the bioactive mCRP induced cell proliferation at lower concentration (i.e. $5 \mu \mathrm{g} / \mathrm{mL}$ ) than previously used. Our present study showing mCRP proangiogenic effects using BAEC support and extend our previous studies using human artery and human aortic endothelial cells [5]. In addition, many clinical observations reported that increased atherosclerotic intraplaque neovascularization plays an important role in plaque progression, plaque instability, and rupture of plaque with risk of haemorrhage [28]. These results reinforce the correlation between mCRP overexpression and unstable plaques through mCRP proangiogenic effects.

From our previous study showing that mCRP pro-angiogenic effects up-regulated endothelial Notch-3 gene expression [5], we investigated the role of Notch-3 signalling activation in endothelial cells and established its role in mCRP pro-angiogenic effects. Notch-3 receptor was activated by the use of low concentration $(20 \mathrm{ng} / \mathrm{mL})$ of a chimera protein called Notch-3/Fc and 
its activation was revealed by the detection of a Notch-3 intracellular domain (NICD) fragment analysed by Western blotting. This NICD fragment derived from Notch-3 activation was released after protein cleavage under the action of the $\gamma$-secretase, within the lipid bilayer [29], which could be initiated by the use of the cell-permeable $\gamma$-secretase inhibitor DAPT. Although Notch-1 and Notch-4 are predominantly expressed in the endothelium [30], while Notch-3 receptor is more commonly expressed by smooth muscle cells, we have previously shown that Notch-3 receptor expression is not restricted to smooth muscle cells, but can be detected in cultured aortic endothelial cells [5]. During sprouting angiogenesis, Notch signalling plays a central role in the coordination of cellular behaviours on "stalk" growing cells and on "tip" leading endothelial cells through the modulation of VEGF-mediated angiogenesis [31]. Many reports have described that Notch inactivation using DAPT promoted angiogenesis including increased cell migration and tube formation [32-34]. Here, cultured endothelial cells treated with DAPT, thereby blocking Notch signalling significantly promoted angiogenesis. These data support the angiogenic process being negatively regulated by Notch as previously reported by others [32-34]. Despite this, Notch activation by Notch-3/Fc increased cell proliferation, migration, tube formation and ex ovo neo-vascularization using CAM model. In addition, blocking Notch signalling by DAPT fully inhibited angiogenesis. The body of evidence indicates the critical existence of a balance between Delta and Jagged-mediated Notch signalling in controlling the endothelial cell fate such as cell proliferation, survival/apoptosis, migration and cell differentiation $[35,36]$. It has been demonstrated that Jagged 1 competition with Dll-4 will result in partial inhibition of Dll4-mediated signalling and promotion of angiogenesis through enhanced sprouting of endothelial cells [37]. Recently, Xu and his colleagues (2009) reported the central role of Notch signalling activation in the induction of bone marrow stromal cell 
differentiation into endothelial cells and in the increase of cell proliferation and tube formation [38]. This was an exciting discovery, suggesting that blocking Notch function in tumour vasculature provides a means by which the tumour growth can be suppressed [39]. Regarding mCRP pro-angiogenic effects, blocking $\gamma$-secretase activity inhibited mCRP-induced tube formation but not mCRP-induced cell proliferation and migration. Recently we have demonstrated the requirement of phospho-insulin receptor substrate-1 (IRS-1) in mCRP-induced cell differentiation and not in mCRP mediating cell proliferation and migration [40]. In addition, IRS-1 has been shown to bind a F-actin binding protein, which has a central role in the reorganisation of the actin cytoskeleton and actin-based cellular functions such as migration and tube formation [41]. Therefore, our present findings reinforce our hypothesis that mCRP induced tube formation in a tri-dimensional Matrigel ${ }^{\mathrm{TM}}$ assay acts through cooperation with another $\gamma$ secretase-dependent transmembrane protein such as insulin growth factor receptor (IGFR).

The addition of the Notch-3 signalling activator to mCRP-induced angiogenesis led to an additive increase of endothelial cell proliferation, migration and tube formation. Indeed, in most of the assays, the cell response induced by the two factors together was higher than the one induced by a single stimulation. These results clearly suggest the existence of common (crosstalk) signalling pathways induced through the mCRP receptor and the Notch-3 receptor. The Notch signalling was recently shown to operate via the PI3K/Akt pathway [21]; therefore we investigated the importance of the PI3K/Akt pathway in angiogenesis mediated by mCRP and Notch signalling. Here, we showed that both mCRP and Notch-3/Fc enhanced pAkt expression and also increased p-eNOS expression (data not shown). Furthermore, the combination of mCRP with Notch-3/Fc induced a higher increase of p-Akt expression than single (mCRP or Notch3/Fc) stimulatory factors alone. To demonstrate the PI3K/Akt pathway as a common signalling 
pathway induced by mCRP and Notch-3/Fc, we used the pharmacological inhibitor of PI3K pathway (LY294002) and of $\gamma$-secretase activity (DAPT) in all in vitro angiogenesis assays. The addition of LY294002 resulted in the loss of pro-angiogenic effects of mCRP and Notch-3/Fc and the loss of their additive effects which highlighted their common angiogenic signalling pathway through the PI3K survival pathway. The importance of the survival pathway in mCRPand Notch-3 signalling-promoted angiogenesis was also confirmed using the in vivo CAM assay. The strongest inhibition of angiogenesis induced by the combined effect of mCRP with Notch3/Fc was obtained after the blockade of PI3K/Akt survival pathway (Figure 7). Surprisingly, the blockade of $\gamma$-secretase activity and PI3K/Akt pathway in the CAM assay did not fully inhibit the pro-angiogenic effects induced by the combined mCRP with Notch-3/Fc. This finding suggests that activation of other angiogenic signalling pathways occur in compensation to the blockade of both mCRP and Notch-3 signalling pathways.

To get a better understanding of the cell behaviour and the vascular cell interactions involved during sprouting angiogenesis, tri-dimensional BAEC/SMC co-culture spheroids were embedded in type I collagen gel. Using transmission electron microscopy (TEM), some differences in vascular cell organization were highlighted during the sprouting angiogenesis showing discontinuous and continuous vascular sprout structures induced by mCRP and Notch-3/Fc, respectively. Regarding the continuous vascular sprout structures induced by Notch-3/Fc, it is widely defined that heterotypic Notch signalling from endothelial cells to smooth muscle cells is critical for vessel stabilization and maturation [42]. In addition, endothelial cell autonomous Notch signalling regulates endothelial cell branching during sprouting angiogenesis [32]. The discontinuous vascular system induced by mCRP consists of gaps between adjoining cells, suggesting mCRP could be a key contributor to leakage because of the lack of interactions 
between the cells. A closer analysis of vascular cell organization during sprouting angiogenesis using TEM has revealed for the first time that mCRP induced the formation of finer filopodia displayed by some vascular cells. Using a human pro-monocytic cell line (U937), Ciubotaru and colleagues [43] have described an association of this aspect of filopodia formation and cell polarization with the increase of CRP expression which reflected its potential role in the cytoskeletal rearrangement.

To study the mechanism underpinning vascular cell interactions associated with mCRP and Notch-induced sprouting angiogenesis, we targeted two transmembrane adhesion molecules: vascular endothelial (VE)-cadherin, known to play a critical role in vascular barrier integrity [44], and neural (N)-cadherin, thought to be essential for interactions between endothelial and mural cells with stabilization of nascent blood vessels by mural cells [45]. Using aortic EC and SMC co-cultured on type I collagen gel, followed by Western blotting we showed that mCRP but not Notch-3/Fc induced VE-cadherin expression in vascular cells. However, the combination of mCRP with Notch-3/Fc induced the disappearance of VE-cadherin expression. These results strengthened other reports that VE-cadherin expression disappears during the angiogenic process to increase the motility capacity of the activated endothelial cells [46]. Regarding N-cadherin expression, both mCRP and Notch-3/Fc independently and together up-regulated N-cadherin expression in vascular cells cultured on collagen gel, reinforcing the possibility of stabilization and thickening of the vascular structures previously observed in the sprouting angiogenesis assay. One study reported that mCRP induced adhesion molecule expression of inflammation including ICAM, VCAM-1 and E-selectin in human endothelial cells [47] however; so far, no studies have checked whether mCRP modulated the expression of adhesion molecules associated with angiogenesis. Here, we are the first to show that mCRP up-regulated VE-cadherin and N- 
cadherin expression in vascular cells co-cultured on type I collagen gel, together with a Notchinduced down-regulation of VE-cadherin expression and an up-regulatory effect on $\mathrm{N}$-cadherin expression. These data suggest that mCRP combined with Notch signalling might amplify the vascular remodelling process, via VE-cadherin, with subsequent stabilization of the vascular structures via $\mathrm{N}$-cadherin.

Taken together, in this study we provide the first insight demonstrating an additive effect of mCRP with the Notch-3 signalling activator chimera protein (Notch-3/Fc) through the PI3K/Akt survival pathway, leading to increased angiogenesis and a greater stability of vascular structures by modulating VE-cadherin and N-cadherin expression (Figure 7). Thus, mCRP with Notch-3 activator therapeutically combined could promote and stabilize vessel formation whilst reducing the risk of haemorrhage from unstable plaque or immature blood vessels in vascular diseases. 


\section{Acknowledgments}

We would like to thank Dr Alexandr Mironov (University of Manchester, UK) for performing the transmission electronic microscopy and also thank C.-Y. Yeung and K. E. Kadler (university of Manchester, UK) for use of egg incubator facilities (Wellcome Trust grant 076939/Z/05/Z).

\section{Conflict of interest}

The authors declare that they have no conflict of interest. 


\section{References}

[1] J. Folkman, Angiogenesis in cancer, vascular, rheumatoid and other disease, Nat. Med. 1 (1995) 27-31.

[2] L.C. Albuquerque, L.B. Narvaes, A.A. Maciel, H. Staub, M. Friedrich, J.R. Filho, M.B. Marques, L.E. Rhode, Intraplaque hemorrhage assessed by high-resolution magnetic resonance imaging and C-reactive protein in carotid atherosclerosis, J. Vasc. Surg. 46 (2007) 1130-1137.

[3] M. Slevin, N. Rovira, M. Turu, A. Luque, L. Badimon, J. Gaffney, L.M. Potempa, J. Krupinski, Modified C-reactive protein is expressed in adventitia and intimal neovessels from complicated regions of unstable carotid plaques, The open circulation and vascular journal 2 (2009) 23-29.

[4] M. Slevin, S. Matou-Nasri, M. Turu, A. Luque, N. Rovira, L. Badimon, S. Boluda, L. Potempa, C. Sanfeliu, N. de Vera, J. Krupinski, Modified C-reactive protein is expressed by stroke neovessels and is a potent activator of angiogenesis in vitro, Brain Pathol. 20 (2010) 151165.

[5] M.M. Turu, M. Slevin, S. Matou, D. West, C Rodrígues, A. Luque, M. Grau-Olivares, L. Badimon, J. Martinez-Gonzales, J. Krupinski, C-reactive protein exerts angiogenic effects on vascular endothelial cells and modulates associated signalling pathways and gene expression, BMC Cell Biol. 9 (2008) 47.

[6] A.K. Shrive, G.M. Cheetham, D. Holden, D.A. Myles, W.G. Turnell, J.E. Volanakis, M.B. Pepys, A.C. Bloomer, T.J. Greenhough, Three dimensional structure of human C-reactive protein, Nat. Struct. Biol. 3 (1996) 346-354.

[7] S. Depraetere, J. Willems, M. Joniau, Stimulation of CRP secretion in HepG2 cells: cooperative effect of dexamethasone and interleukin 6, Agents Actions. 34 (1991) 369-375.

[8] S.R. Ji, Y. Wu, L. Zhu, L.A. Potempa, F.L. Sheng, W. Lu, J. Zhao, Cell membranes and liposomes dissociate C-reactive protein (CRP) to form a new, biologically active structural intermediate: mCRP(m), FASEB J. 21 (2007) 284-94.

[9] S.U. Eisenhardt, J. Habersberger, A. Murphy, Y.C. Chen, K.J. Woollard, N. Bassler, H. Qian, C. von Zur Muhlen, C.E. Hagemeyer, I. Ahrens, J. Chin-Dusting, A. Bobik, K. Peter, Dissociation of pentameric to monomeric C-reactive protein on activated platelets localizes inflammation to atherosclerotic plaques, Circ. Res. 105 (2009) 128-137.

[10] J.J. Kreiss, L.A. Potempa, B.E. Anderson, Conversion of native oligomeric to a modified monomeric form of human C-reactive protein, Int. J. Biochem. Cell Biol. 30 (1998) 1415-1426. 
[11] S. Devaraj, T.W. Du Clos, I. Jialal, Binding and internalization of C-reactive protein by Fcgamma receptors on human aortic endothelial cells mediates biological effects, Arterioscler. Thromb. Vasc. Biol. 25 (2005) 1359-1363.

[12] K.E. Taylor, C.W. van den Berg, Structural and functional comparison of native pentameric, denatured monomeric and biotinylated C-reactive protein, Immunology. 120 (2007) 404-411.

[13] A.F. Siekmann, N.D. Lawson, Notch signalling and the regulation of angiogenesis, Cell Adh. Migr. 1 (2007) 104-106.

[14] L. Scheppke, E.A. Murphy, A. Zarpellon, J.J. Hofmann, A. Merkulova, D.J. Shields, S.M. Weis, T.V. Byzova, Z.M. Ruggeri, M.L. Iruela-Arispe, D.A. Cheresh, Notch promotes vascular maturation by inducing integrin-mediated smooth muscle cell adhesion to the endothelial basement membrane, Blood 119 (2012) 2149-2158.

[15] R.A. Kovall, S.C. Blacklow, Mechanistic insights into Notch receptor signaling from structural and biochemical studies, Curr. Top Dev. Biol. 92 (2010) 31-71.

[16] R. Schwanbeck, S. Martini, K. Bernoth, U. Just, The Notch signaling pathway: molecular basis of cell context dependency, Eur. J. Cell Biol. 90 (2011) 572-581.

[17] K. Niessen, A. Karsan, Notch signaling in the developing cardiovascular system, Am. J. Physiol. Cell Physiol. 293 (2007) C1-11.

[18] H. Liu, W. Zhang, S. Kennard, R.B. Caldwell, B. Lilly, Notch3 is critical for proper angiogenesis and mural cell investment, Cir. Res. 107 (2010) 860-870.

[19] J.F. Arboleda-Velasquez, Z. Zhou, H.K. Shin, A. Louvi, H.H. Kim, S.I. Savitz, J.K. Liao, S. Salomone, C. Ayata, M.A. Moskowitz, S. Artavanis-Tsakonas, Linking Notch signaling to ischemic stroke, Proc. Natl. Acad. Sci. USA. 105 (2008) 4856-4861.

[20] Y. Benabu, M. Beland, N. Ferguson, B. Maranda, R.M. Boucher, Genetically proven cerebral autosomal-dominant arteriopathy with subcortical infarcts and leukoencephalopathy (CADASIL) in a 3-year-old, Pediatr. Radiol. (2013).

[21] J. Yao, C. Qian, Inhibition of Notch3 enhances sensitivity to gemcitabine in pancreatic cancer through an inactivation of PI3K/Akt-dependent pathway, Med. Oncol. 27 (2010) 10171022.

[22] L.A. Potempa, B.A. Maldonado, P. Laurent, E.S. Zemel, H. Gewurz, Antigenic, electrophoretic and binding alterations of human C-reactive protein modified selectively in the absence of calcium, Mol. Immunol. 20 (1983) 1165-1175. 
[23] A. Sattar, P. Rooney, S. Kumar, D. Pye, D.C. West, I. Scott, P. Ledger, Application of angiogenic oligosaccharides of hyaluronan increases blood vessel numbers in rat skin, J. Invest. Dermatol. 103 (1994) 576-579.

[24] S. Matou-Nasri, J. Gaffney, S. Kumar, M. Slevin, Oligosaccharides of hyaluronic induce angiogenesis through distinct CD44 and RHAMM-mediated signalling pathways involving Cdc2 and gamma-adducin, Int. J. Oncol. 35 (2009): 761-773.

[25] J. Angulo, S. Matou, Application of mathematical morphology to the quantification of in vitro endothelial cell organisation into tubular-like structures, Cell Mol. Biol. 53 (2007) 22-35.

[26] K.E. Taylor, J.C. Giddings, C.W. van den Berg, C-reactive protein-induced in vitro endothelial cell activation is an artifact caused by azide and lipopolysaccharide, Arterioscler. Thromb. Vasc. Biol. 25 (2005) 1225-1230.

[27] P. Cirillo, P. Golino, P. Calabrò, G. Calì, M. Ragni, S. De Rosa, G. Cimmino, M. Pacileo, R. De Palma, L. Forte, A. Gargiulo, F.G. Corigliano, V. Angri, R. Spagnuolo, L. Nitsch, M. Chiariello, C-reactive protein induces tissue factor expression and promotes smooth muscle and endothelial cell proliferation, Cardiovasc. Res. 68 (2005) 47-55.

[28] K.R. Purushothaman, M. Purushothaman, P. Muntner, P.A. Lento, W.N. O'Connor, S.K. Sharma, V. Fuster, P.R. Moreno, Inflammation, neovascularization and intra-plaque hemorrhage are associated with increased reparative collagen content: implication for plaque progression in diabetic atherosclerosis, Vasc. Med. 16 (2011) 103-108.

[29] C. Kaether, C. Haass, H. Steiner, Assembly, trafficking and function of gamma-secretase, Neurodegener. Dis. 3 (2006) 275-283.

[30] N. Villa, L. Walker, C.E. Lindsell, J. Gasson, M.L Iruela-Arispe, G. Weinmaster, Vascular expression of Notch pathway receptors and ligands is restricted to arterial vessels, Mech. Dev. 108 (2001) 161-164.

[31] I. Geudens, H. Gerhardt, Coordinating cell behaviour during blood vessel formation, Development. 138 (2011) 4569-4583.

[32] R.C. Sainson, J. Aoto, M.N. Nakatsu, M. Holderfield, E. Conn, E. Koller, C.C. Hughes, Cell-autonomous notch signaling regulates endothelial cell branching and proliferation during vascular tubulogenesis, FASEB J. 19 (2005) 1027-1029.

[33] L. Cao, P.R. Arany, Y.S. Wang, D.J. Mooney, Promoting angiogenesis via manipulation of VEGF responsiveness with notch signaling, Biomaterials. 30 (2009) 4085-4093.

[34] R. Benedito, S.F. Rocha, M. Woeste, M. Zamykal, F. Radtke, O. Casanovas, A. Duarte, B. Pytowski, R.H. Adams, Notch-dependent VEGFR3 upregulation allows angiogenesis without VEGF-VEGFR2 signalling, Nature. 484 (2012) 110-114. 
[35] A. Al Haj Zen, P. Madeddu, Notch signalling in ischaemia-induced angiogenesis, Biochem. Soc. Trans. 37 (2009) 1221-1227.

[36] P. Rizzo, L. Miele, R. Ferrari, The Notch pathway: a crossroad between the life and death of the endothelium, Eur. Heart J. (2012) (PMID: 22645188)

[37] R. Benedito, C. Roca, I. Sörensen, S. Adams, A. Gossler, M. Fruttiger, R.H. Adams, The notch ligands Dll4 and Jagged1 have opposing effects on angiogenesis, Cell. 137 (2009) 11241135

[38] J. Xu, X. Liu, J. Chen, A. Zacharek, X. Cui, S. Savant-Bhonsale, Z. Liu, M. Chopp, Simvastatin enhances bone marrow stromal cell differentiation into endothelial cells via notch signaling pathway, Am. J. Physiol. Cell Physiol. 296 (2009) C535-C543.

[39] N.M. Kofler, C.J. Shawber, T. Kangsamaksin, H.O. Reed, J. Galatioto, J. Kitajewski, Notch signaling in developmental and tumor angiogenesis, Genes Cancer. 2 (2011) 1106-11 16.

[40] M. Slevin, L. Badimon, S. Matou, R. AL Baradie, J. Krupinski, Increased monomeric Creactive expression after brain damage may be involved in promotion of vascular pathology including Alzheimer's and tumour growth, Asian J. Cancer. 11 (2012) 210-214.

[41] A. Lee, F. Hakuno, P. Northcott, J.E. Pessin, M. Rozakis Adcock, Nexilin, a cardiomyopathy-associated F-actin binding protein, binds and regulates IRS1 signaling in skeletal muscle cells, PLoS One 8 (2013) e55634.

[42] R.C. Sainson, A.L. Harris, Regulation of angiogenesis by homotypic and heterotypic notch signalling in endothelial cells and pericytes: from basic research to potential therapies, Angiogenesis. 11 (2008) 41-51.

[43] I. Ciubotaru, L.A. Potempa, R.C. Wander, Production of modified C-reactive protein in U937-derived macrophages, Exp. Biol. Med. 230 (2008) 762-770.

[44] E.S. Harris, W.J. Nelson, VE-cadherin: at the front, center, and sides of endothelial cell organization and function, Curr. Opin. Cell Biol. 22 (2010) 651-658.

[45] J.H. Paik, A. Skoura, S.S. Chae, A.E. Cowan, D.K. Han, R.L. Proia, T. Hla, Sphingosine 1phosphate receptor regulation of $\mathrm{N}$-cadherin mediates vascular stabilization, Genes Dev. 18 (2004) 2392-2403.

[46] Y. Wallez, I. Vilgrain, P. Huber, Angiogenesis: the VE-cadherin switch, Trends Cardiovasc. Med. 16 (2006) 55-59.

[47] T. Khreiss, L. József, L.A. Potempa, J.G. Filep, Conformational rearrangement in C-reactive protein is required for proinflammatory actions on human endothelial cells, Circulation. 109 (2004) 2016-2022. 


\section{Figure legends}

Figure 1. (A) Representative gel electrophoresis of RT-PCR products $\left(A_{1}\right)$ showing $m C R P$ up-regulated Notch-3 gene expression in BAEC. $\left(\mathbf{A}_{2}\right)$ The bar graph shows the expression of bovine Notch-3 relative to control cells given an arbitrary value of 1.0 using bovine S14 ribosomal housekeeping gene expression as a loading control. The data present the mean $\pm \mathrm{SD}$. $(*)$ and $(* *)$ signify a statistically significant difference $(\mathrm{p}<0.05$ and $\mathrm{p}<0.01)$ compared to the control, from three independent experiments. (B) Representative Western blot $\left(\mathbf{B}_{1}\right)$ showing the expression of NICD fragments generated after Notch-3 signalling activation induced by Notch-3/Fc. $\left(\mathbf{B}_{2}\right)$. The bar graph shows the expression of bovine Notch-3 intracellular domain (NICD) relative to control cells given an arbitrary value of 1.0 using tubulin expression as a loading control. The data present the mean \pm SD. $(* *)$ signifies a statistically significant difference $(p<0.01)$ compared to the control, from three independent experiments.

Figure 2. Additive pro-angiogenic effects of mCRP combined with Notch-3/Fc on BAEC

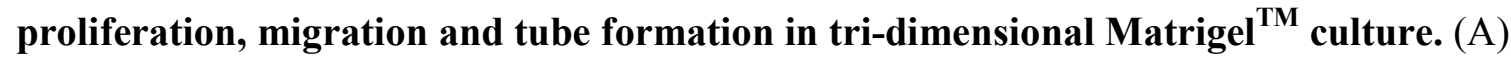
After 3 days of incubation, the cells were counted using a Coulter counter. The bar graph shows the stimulatory effects of $5 \mu \mathrm{g} / \mathrm{mL} \mathrm{mCRP}, 20 \mathrm{ng} / \mathrm{mL}$ Notch-3/Fc and the combination mCRP with Notch-3/Fc on BAEC proliferation. The data present the mean $\pm \mathrm{SD} .\left(^{*}\right)$ and $(* *)$ signify a statistically significant difference $(\mathrm{p}<0.05$ and $\mathrm{p}<0.01)$ compared to the control $(\mathrm{n}=3)$. (B) Representative photomicrographs (x400 magnification) showing the migration of untreated BAEC (Bi) and BAEC treated with mCRP (Bii), Notch-3/Fc (Biii) and the combination mCRP with Notch-3/Fc (Biv). The bar graph (Bv) shows the stimulatory effects of mCRP, Notch-3/Fc and their combination on the distance of migration (black bar) and on the number of migrated 
cells (grey bar) after $24 \mathrm{~h}$ incubation. Scale bar $=100 \mu \mathrm{m}$. (C) Representative photomicrographs (x100 magnification) showing the tube formation of untreated BAEC (Ci) and BAEC treated with mCRP (Cii), Notch-3/Fc (Ciii) and the combination mCRP with Notch-3/Fc (Civ). Lined by the tubes, the closed areas (an example indicated by the arrow) were counted as a parameter for quantification of tubulogenesis. The bar graph $(\mathrm{Cv})$ shows the stimulatory effects of mCRP, Notch-3/Fc and their combination on the promotion of tube formation within $24 \mathrm{~h}$ incubation. The data present the mean $\pm \mathrm{SD} .(*),(* *)$ and $(* * *)$ signify a statistically significant difference $(\mathrm{p}<0.05, \mathrm{p}<0.01$ and $\mathrm{p}<0.001)$ compared to the control, from three independent experiments.

Figure 3. (A) Representative Western blot $\left(A_{1}\right)$ showing the additive upregulation of phospho-Akt expression induced by mCRP, Notch-3/Fc and the combination mCRP in cultured BAEC. $\left(\mathbf{A}_{2}\right)$ The bar graph shows the expression of phospho-Akt expression relative to control cells given an arbitrary value of 1.0 using total Akt as a loading control after $10 \mathrm{~min}$ treatment of the BAEC with mCRP, Notch-3/Fc and the combination of mCRP with Notch-3/Fc. The data present the mean $\pm \mathrm{SD} .(*),(* *)$ and $(* * *)$ signify a statistically significant difference $(\mathrm{p}<0.05, \mathrm{p}<0.01$ and $\mathrm{p}<0.001)$ compared to the control, from three independent experiments.

\section{(B) Effects of DAPT and LY294002 on mCRP, Notch-3/Fc and the combination mCRP}

\section{with Notch-3/Fc-induced phospho-Akt expression in cultured BAEC. Representative}

Western blots of three independent experiments showing the variation of p-Akt expression after 10 min treatment of the BAEC with mCRP, Notch-3/Fc or the combination of mCRP with Notch-3/Fc in the presence or absence of DAPT, LY294002 or together. Total Akt was used as loading controls. 
Figure 4. Effects of LY294002 (PI-3 kinase inhibitor) and DAPT ( $\gamma$-secretase inhibitor) in pro-angiogenic activities of $\mathrm{mCRP}$, Notch-3/Fc and their combination on vascular cells. (A) The bar graph shows the effects of LY294002 and DAPT on mCRP, Notch-3/Fc or their combination-induced BAEC proliferation. Both mCRP and Notch-3/Fc lost their mitogenic effects on EC proliferation after LY294002 treatment. The addition of DAPT blocked Notch3/Fc mitogenic effect but not mCRP. (B) The bar graph shows the effects of inhibitors on BAEC migration (including the distance of migration, black bar and the number of migrated cells, grey bar) induced by mCRP, Notch-3/Fc or the combination mCRP with Notch-3/Fc. Both mCRP and Notch-3/Fc lost their stimulatory effects on EC migration after LY294002 treatment. The addition of DAPT blocked Notch-3/Fc positive effect but not mCRP. (C) The bar graph shows the effects of inhibitors on BAEC tube formation induced by mCRP, Notch-3/Fc or the combination mCRP with Notch-3/Fc. Both mCRP and Notch-3/Fc enhanced their positive effects on EC tube formation after LY294002 treatment. The addition of DAPT totally inhibited mCRP or Notch-3/Fc-induced tube formation. The data present the mean $\pm \mathrm{SD}$. (*) and (**) signify a statistically significant difference $(p<0.05$ and $p<0.01)$ compared to the control $(n=3)$.

Figure 5. Additive pro-angiogenic effects of combined with Notch-3/Fc on neo-blood vessel formation of the chick chorioallantoic membrane. (A) Representative photomicrographs showing the formation of neo-blood vessels (representative examples indicated with arrows) on untreated chorioallantoic membrane (Ai), on chorioallantoic membrane treated with mCRP (Aii), Notch-3/Fc (Aiii) and mCRP combined with Notch-3/Fc (Aiv). The pro-angiogenic effect of the combination mCRP with Notch-3/Fc (Aiv) displayed an additive increase of neo-blood vessel 
formation. The bar graphs $(B)$ and $(C)$ show the mean \pm SD of the vessel number with the branch-point density and the vessel area density measured in each condition of five experiments, respectively. $(*),(* *)$ and $(* * *)$ signify a statistically significant difference $(\mathrm{p}<0.05, \mathrm{p}<0.01$ and $\mathrm{p}<0.001)$ compared with the control. Scale bar $=100 \mu \mathrm{m}$. (D) Effects of LY294002 (PI-3 kinase inhibitor), DAPT ( $\gamma$-secretase inhibitor) and together in neo-blood vessel formation of the chorioallantoic membrane induced by mCRP combined with Notch-3/Fc. At the difference of the aforementioned treatments, the addition of LY294002 strongly inhibited mCRP with Notch-3/Fc-induced angiogenesis in vivo. The bar graph shows the mean $\pm \mathrm{SD}$ of the vessel number density normalised to the control and expressed in percentage of five experiments. $\left(^{*}\right)$ and $(* *)$ signify a statistically significant difference $(\mathrm{p}<0.05$ and $\mathrm{p}<0.01)$ compared to the control.

\section{Figure 6. Monomeric CRP combined with Notch-3/Fc induced thicker sprouting} angiogenesis of co-culture spheroids with modulation of VE-cadherin and N-cadherin expression. (A) Representative photomicrographs showing the co-culture spheroids of BAEC/SMC embedded in collagen gel supplemented with basal medium (control, Ai), in the presence or absence of mCRP (Aii), Notch-3/Fc (Aiii), the combined mCRP with Notch-3/Fc (Aiv). After 2-day incubation, both mCRP and Notch-3/Fc increased sprouting angiogenesis and their combination formed thicker and longer sprouts (indicated by the arrows). Scale bar $=100$ $\mu \mathrm{m}$. (B) The bar graph shows the mean \pm SD of the co-cultured sprout length measured in each condition of three experiments. $(*),(* *)$ and $(* * *)$ signify a statistically significant difference $(\mathrm{p}$ $<0.05, \mathrm{p}<0.01$ and $\mathrm{p}<0.001)$ compared with the control. (C) Representative TEM photomicrographs of ultra-structure sprout sections showing the distinct vascular cell 
organisation induced by mCRP, Notch-3/Fc or their combination. Compared to untreated cell organisation forming the sprout $(\mathrm{Ci})$, vascular cells treated with mCRP (Cii) displayed more filopodia (indicated with arrows) with less interaction between the cells at the difference of Notch-3/Fc effect (Ciii). Their combination mCRP with Notch-3/Fc (Civ) induced aligned and thicker sprout structures. (D) Representative Western blots showing VE-cadherin and Ncadherin expression in co-culture spheroids of BAEC/SMC embedded in collagen gel. Compared with untreated cells, mCRP increased both VE-cadherin and N-cadherin expressions whereas Notch-3/Fc down-regulated VE-cadherin and up-regulated N-cadherin expressions. The addition of mCRP to Notch-3/Fc treatment amplified the variation of cadherin expressions induced by Notch-3/Fc resulting in the disappearance of VE-cadherin expression and concomitant increase of $\mathrm{N}$-cadherin. These experiments were performed at least three times. $\beta$ Tubulin was used as loading control.

Figure 7. Schematic diagram showing mCRP and Notch-3 signalling pathways in BAEC converging to PI3K/Akt survival pathway, leading to the activation of gene expressions resulting in increased angiogenesis, which can be inhibited by LY294002 treatment. Using a $\gamma$-secretase inhibitor, DAPT, we demonstrate attenuation of mCRP-induced tube formation in 3D Matrigel $^{\mathrm{TM}}$ culture, suggesting the requirement of transmembrane or downstream protein-dependents $\gamma$ secretase activities and causing actin cytoskeleton reorganization such as IRS-1. The plain and dashed arrows indicate the direct and indirect molecular links. 
A

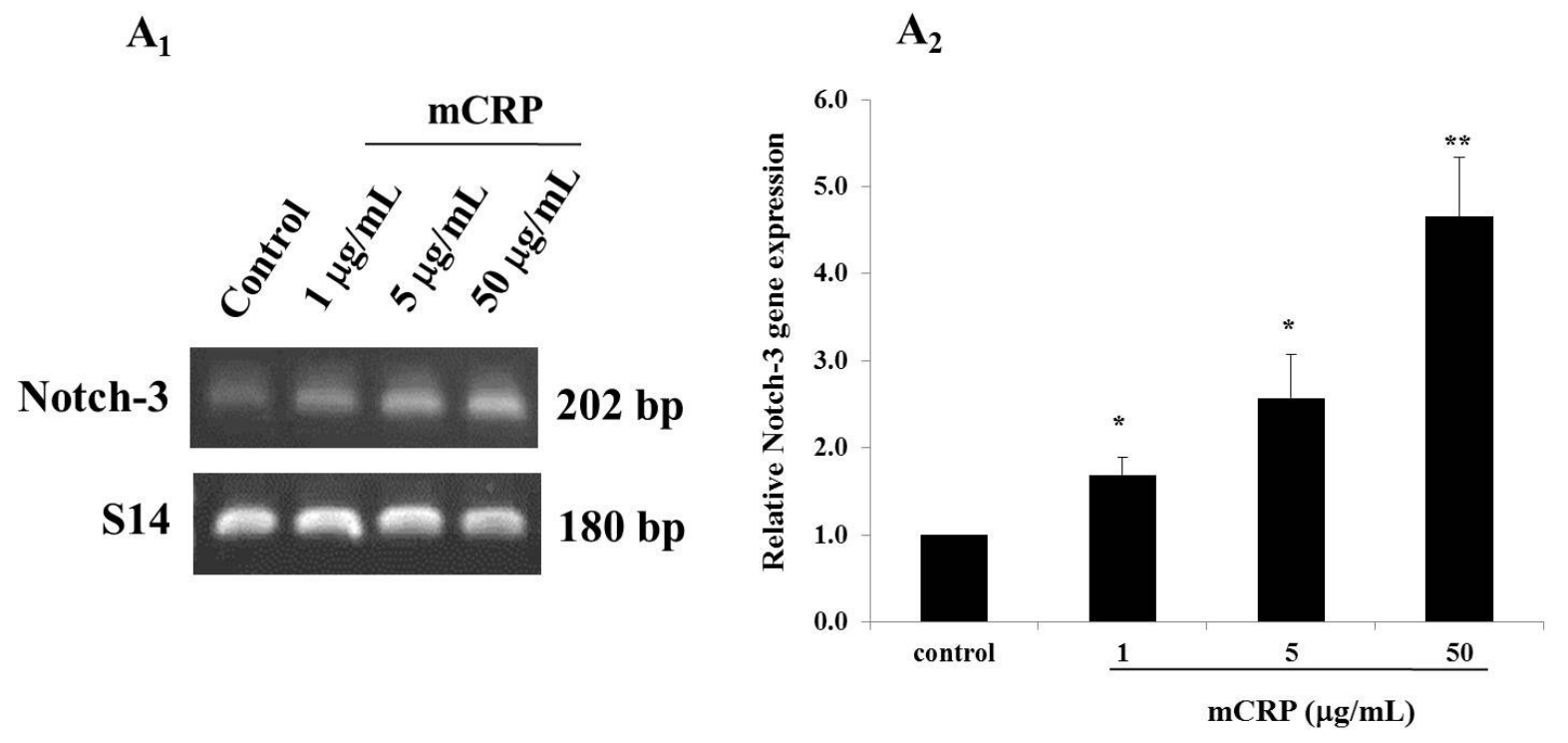

B

$\mathbf{B}_{1}$

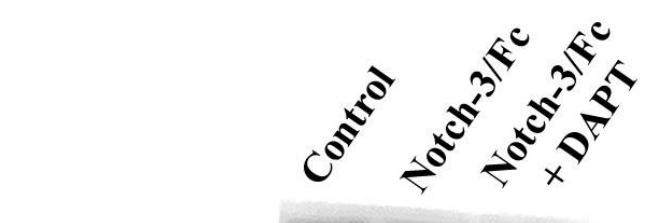

Notch-3 ICD

$\beta$-Tubulin

$55 \mathrm{kDa}$

$120 \mathrm{kDa}$

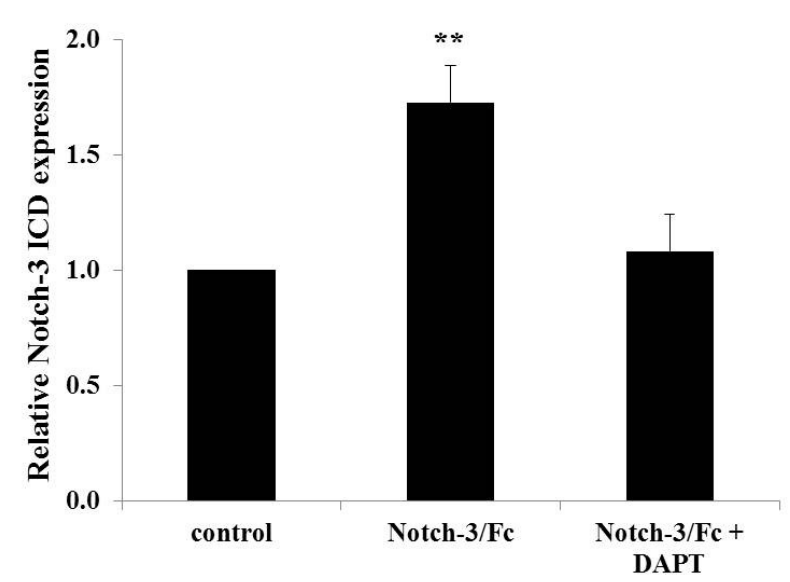

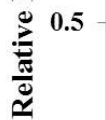

$\mathbf{B}_{2}$

Figure 1 
A

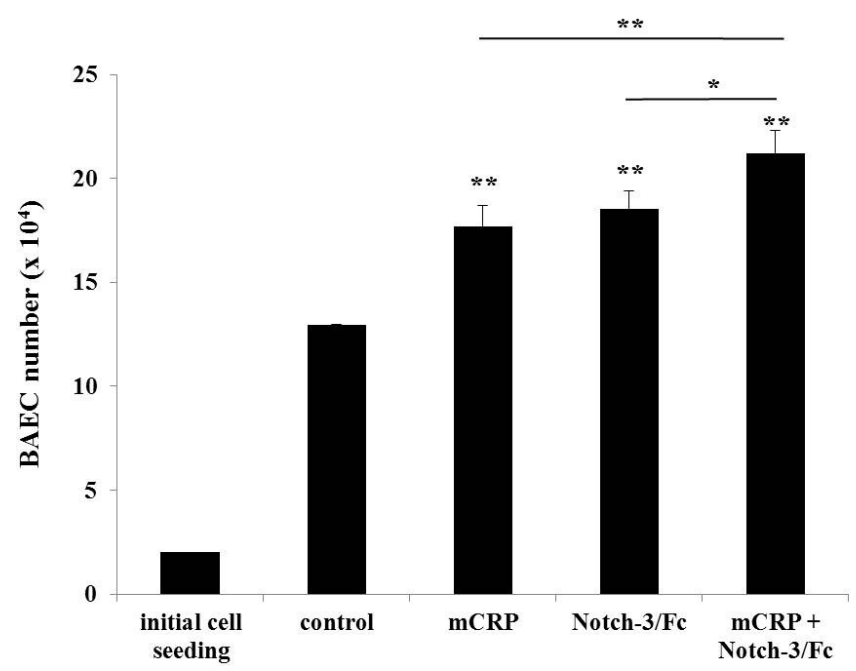

B
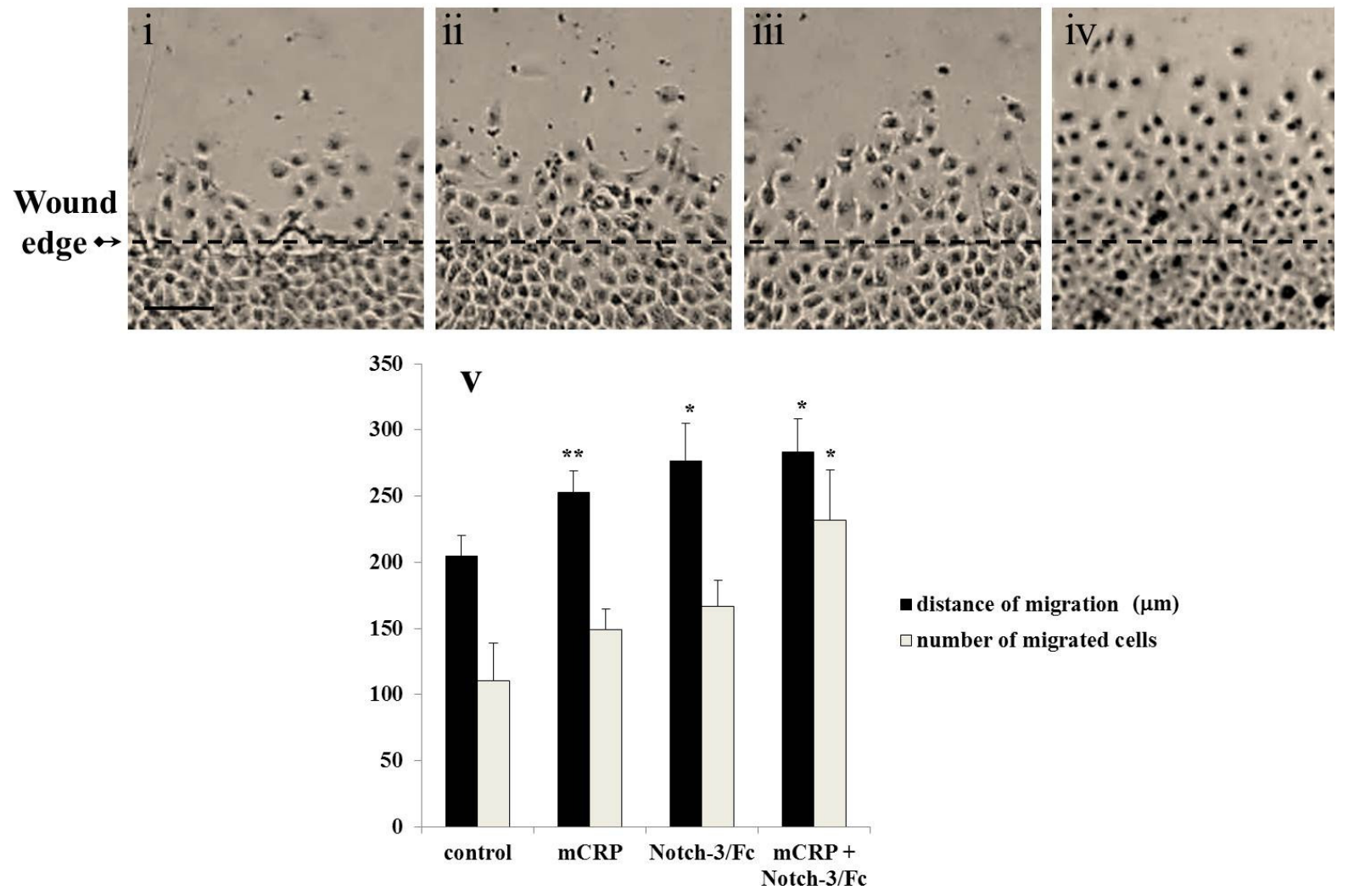

Figure 2 

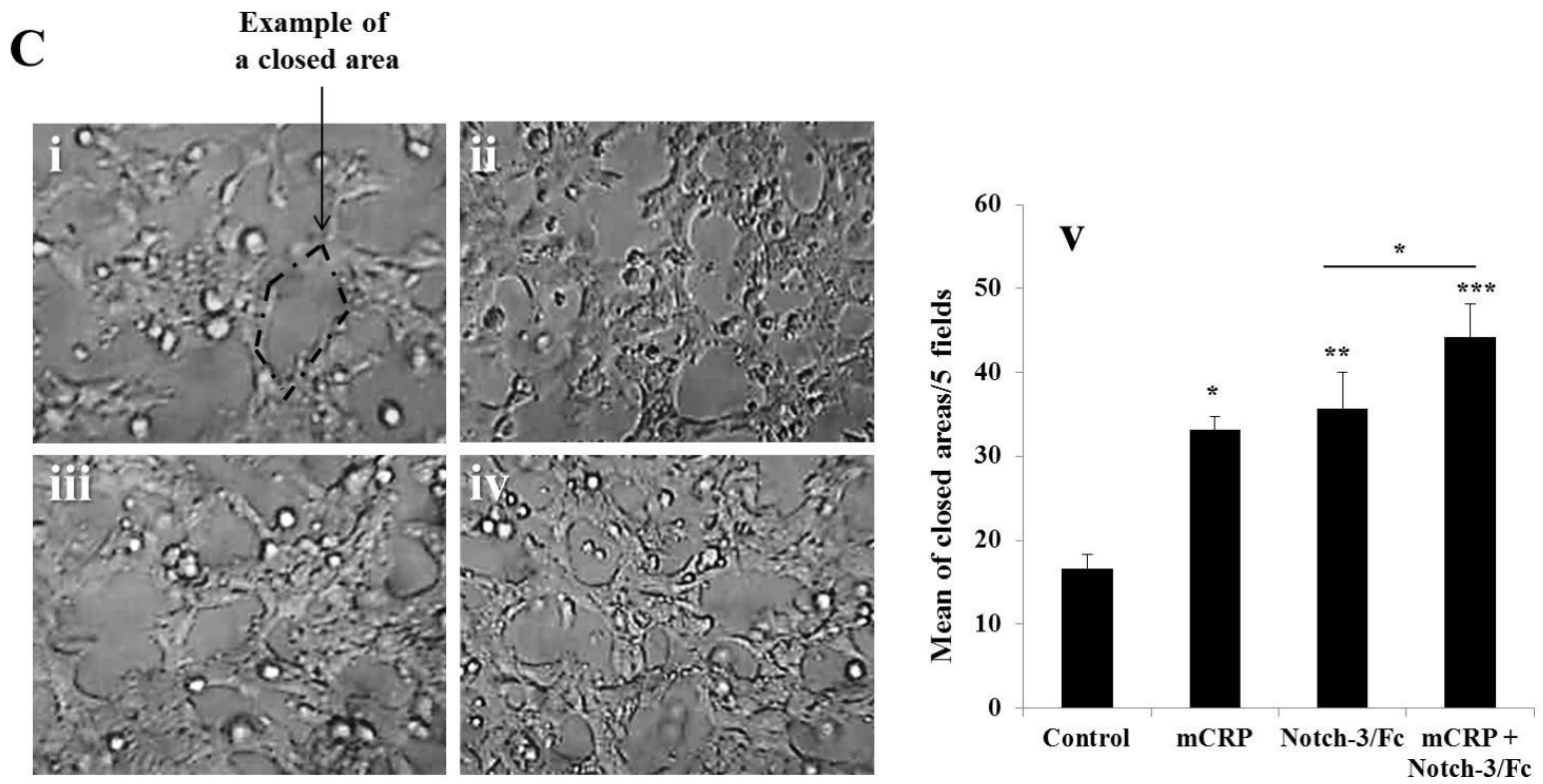

Figure 2 
A

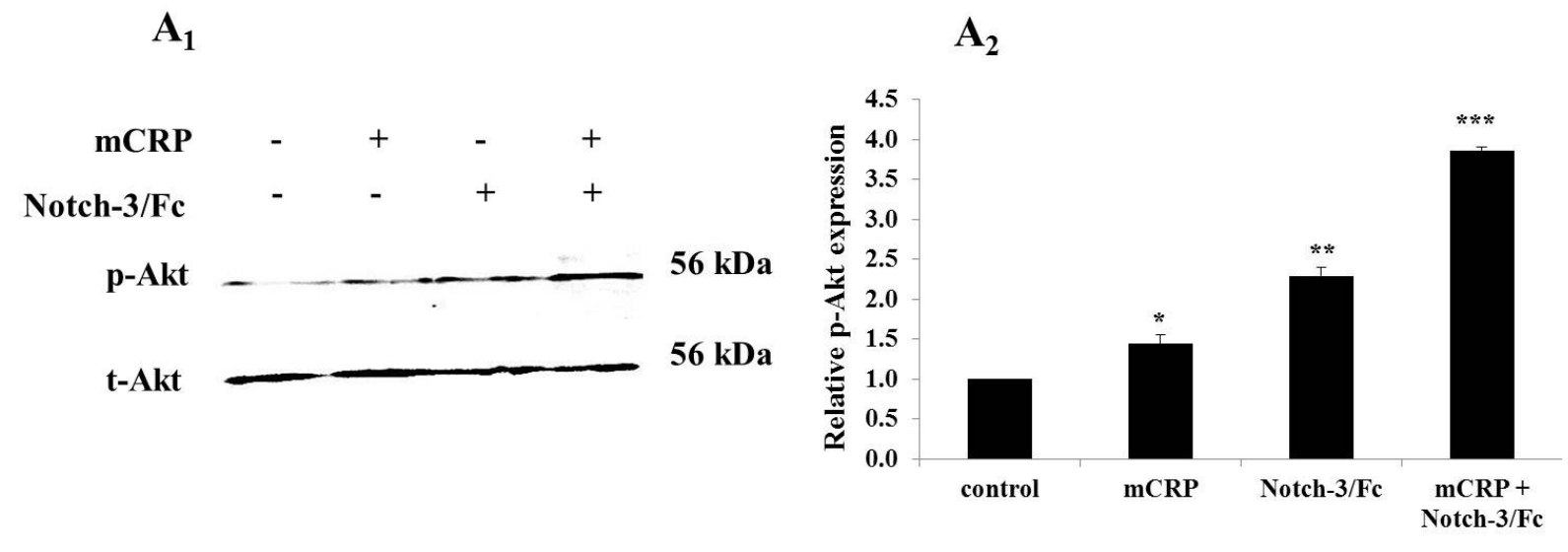

B

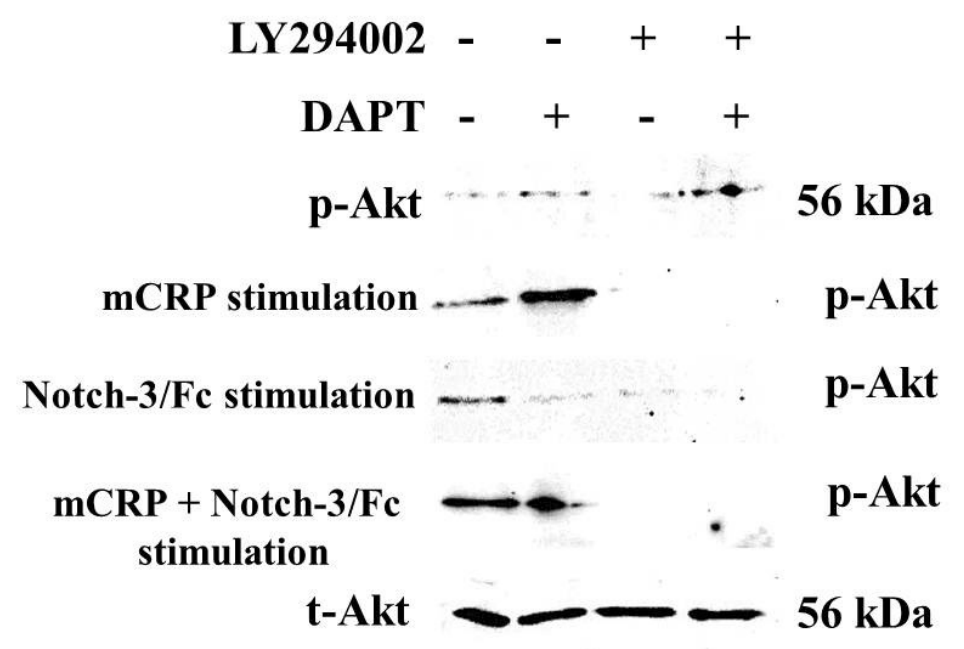

Figure 3 
A. Proliferation

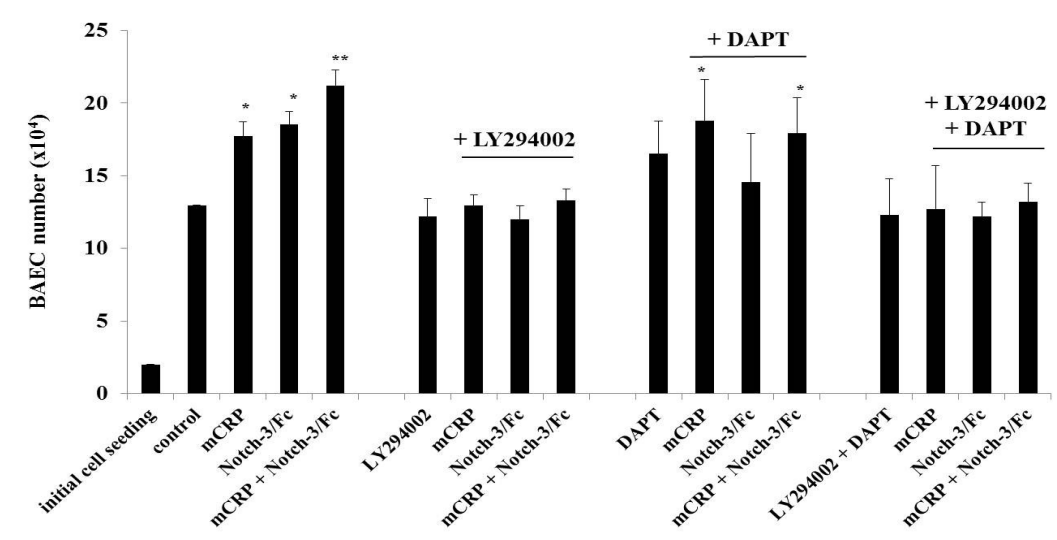

B. Migration

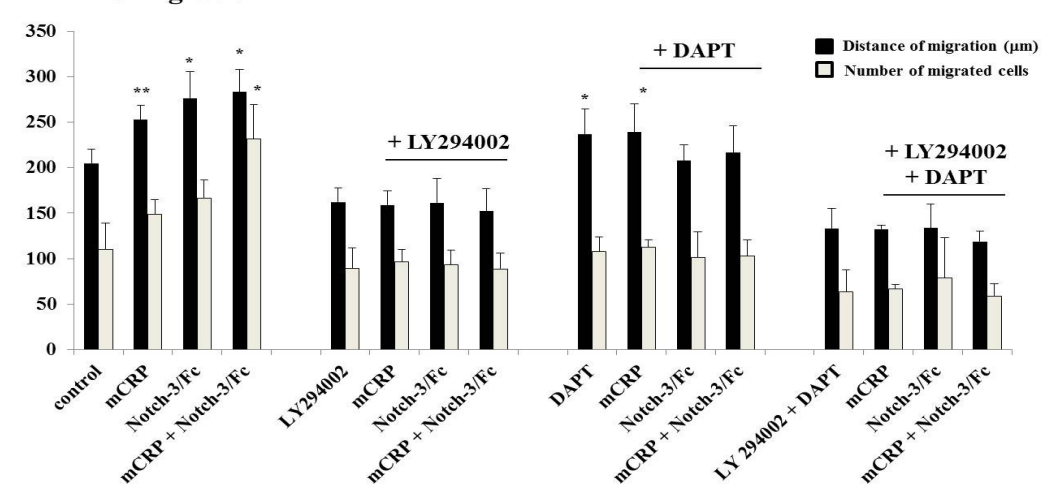

C. Tube formation

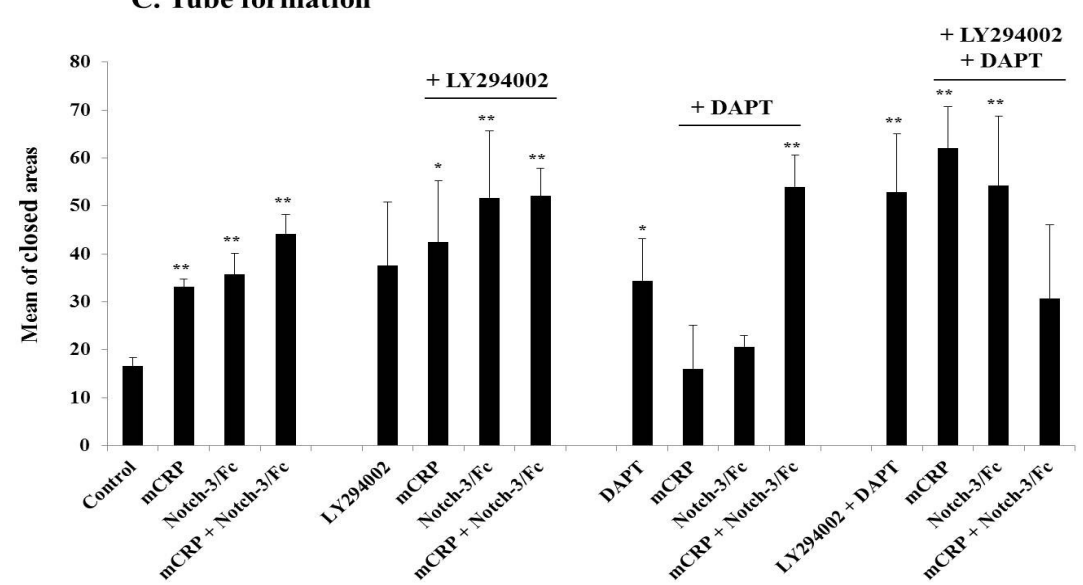

Figure 4 

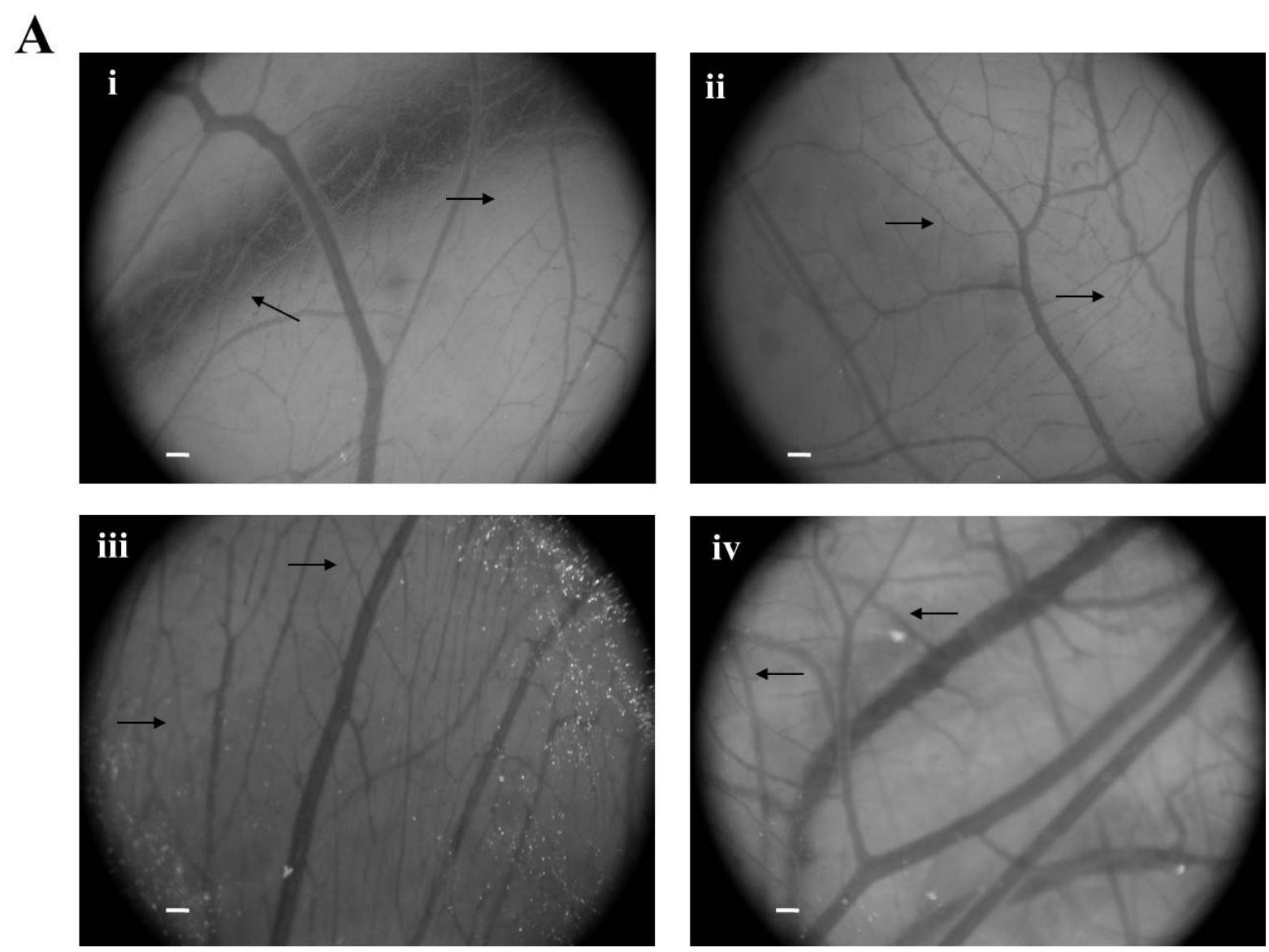

B

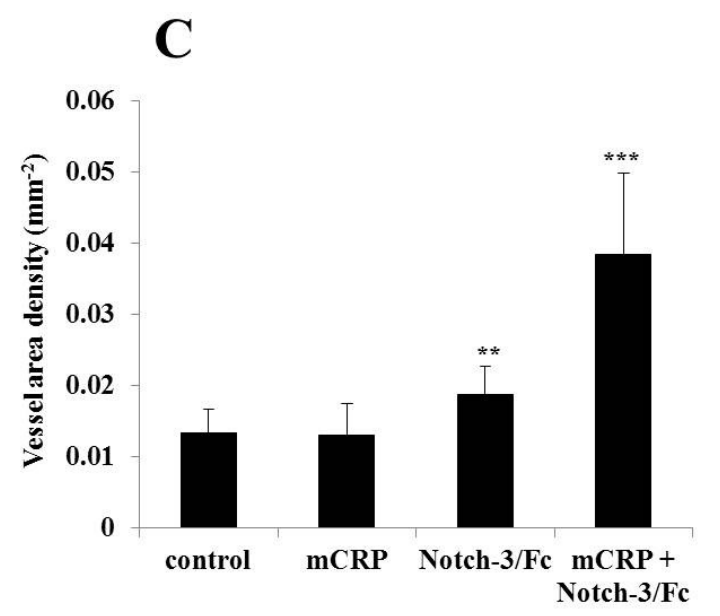

Figure 5 


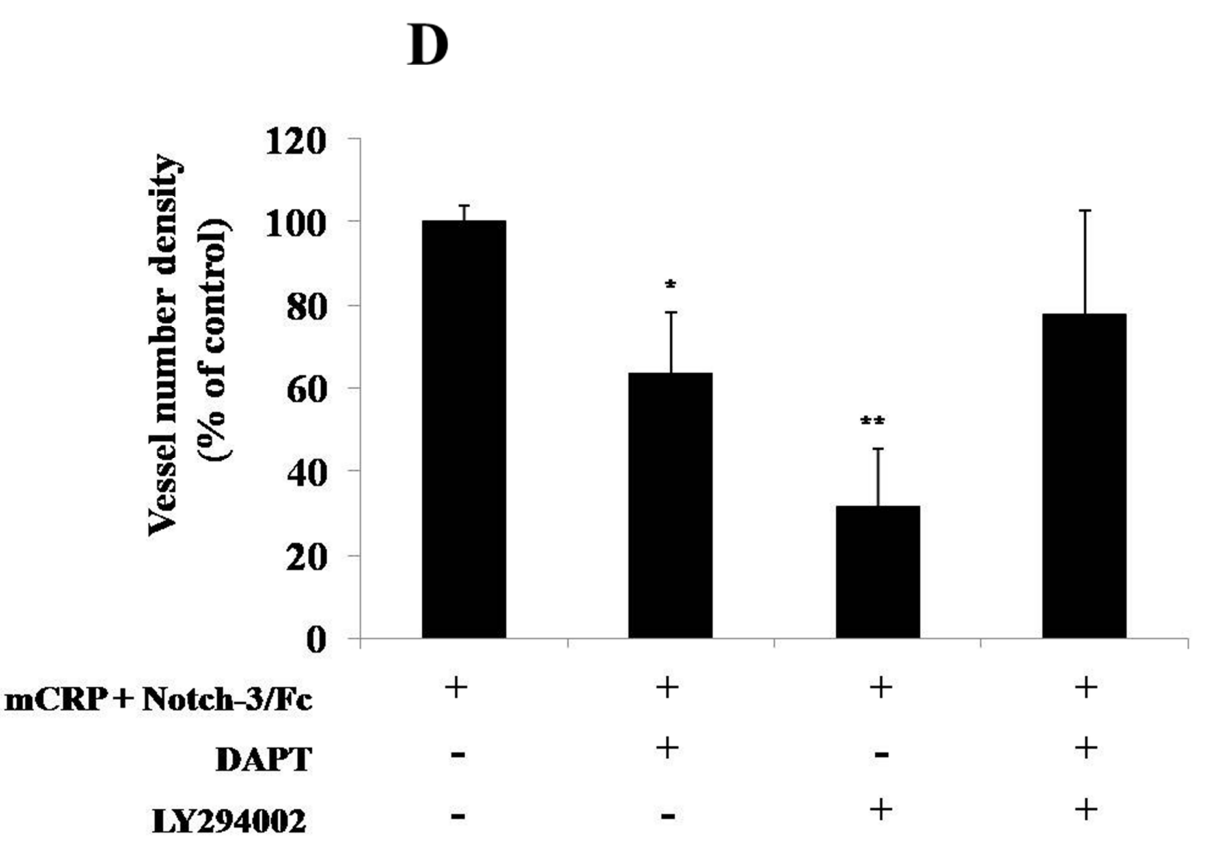

Figure 5 
A
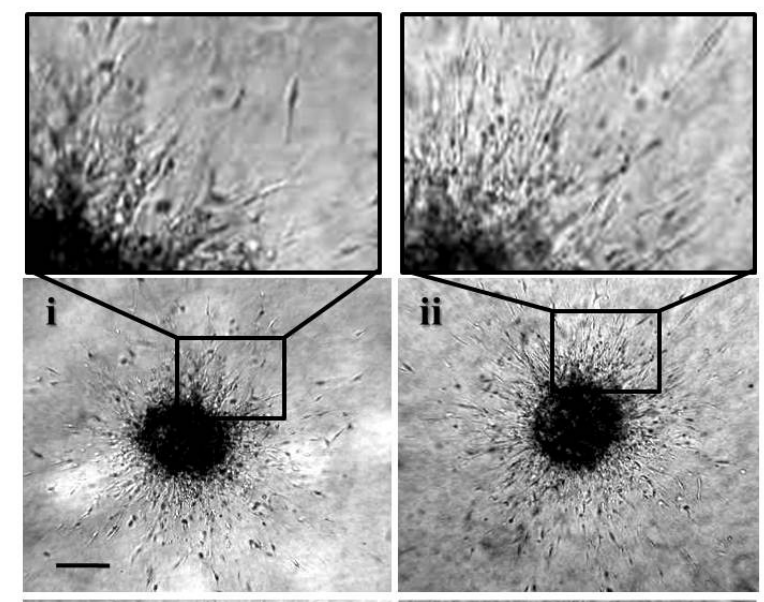

iii

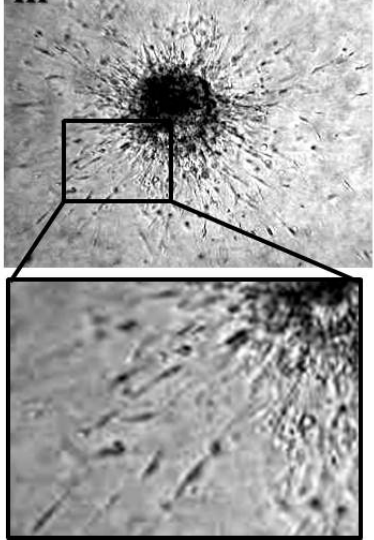

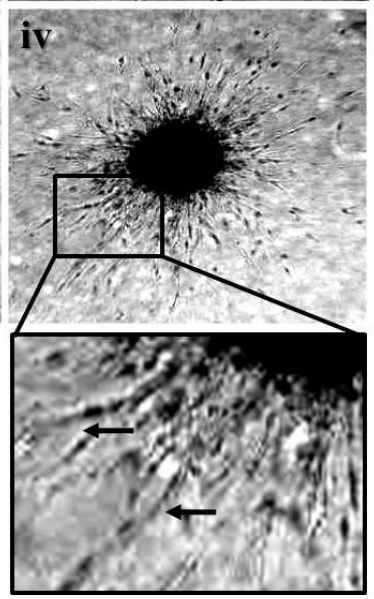

Figure 6

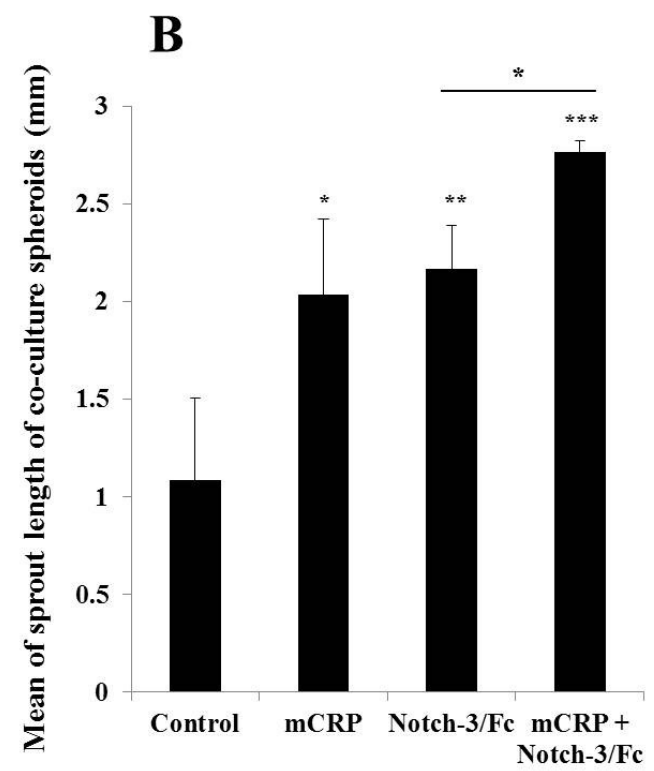




\section{C}
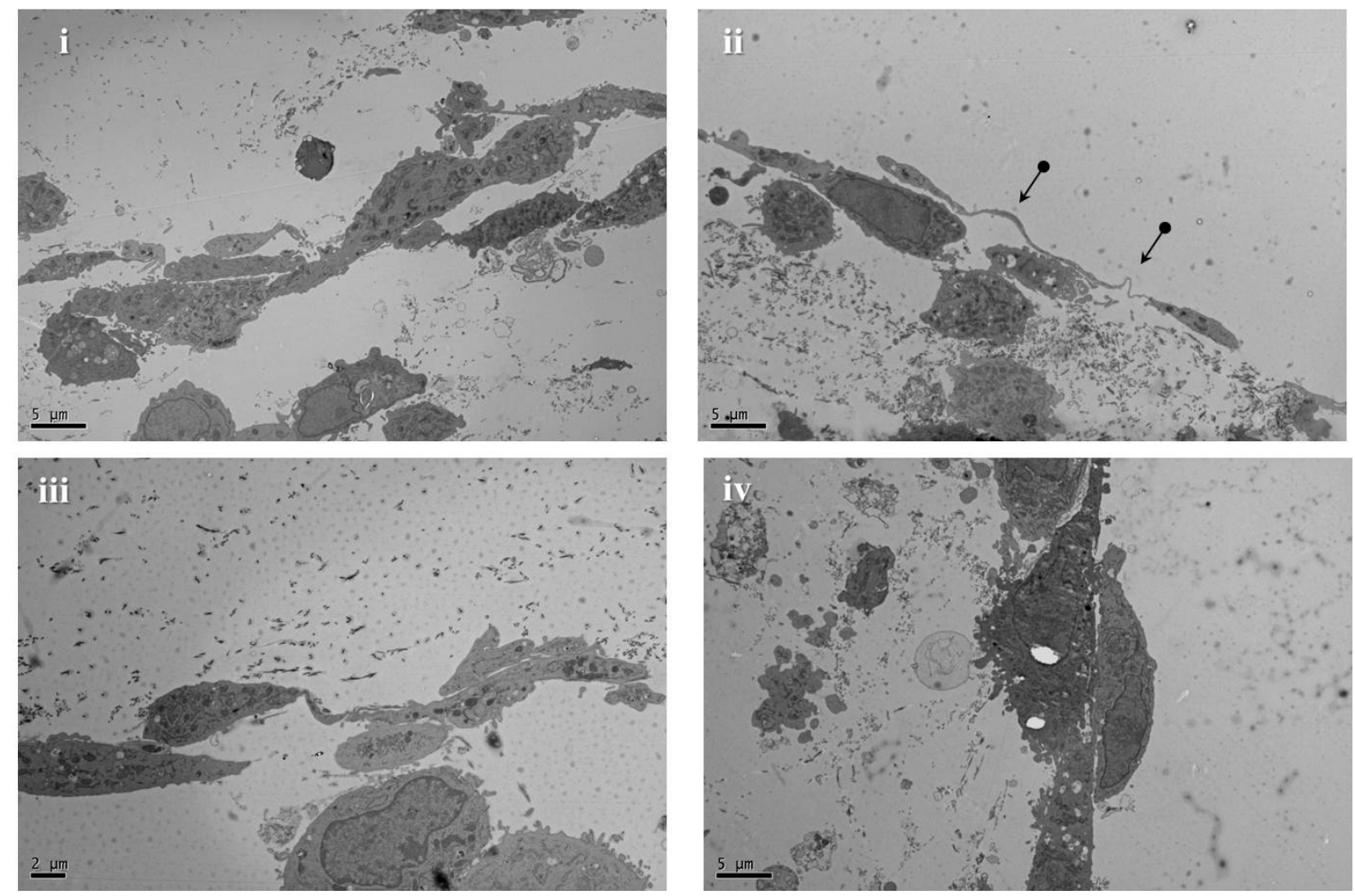

\section{D}

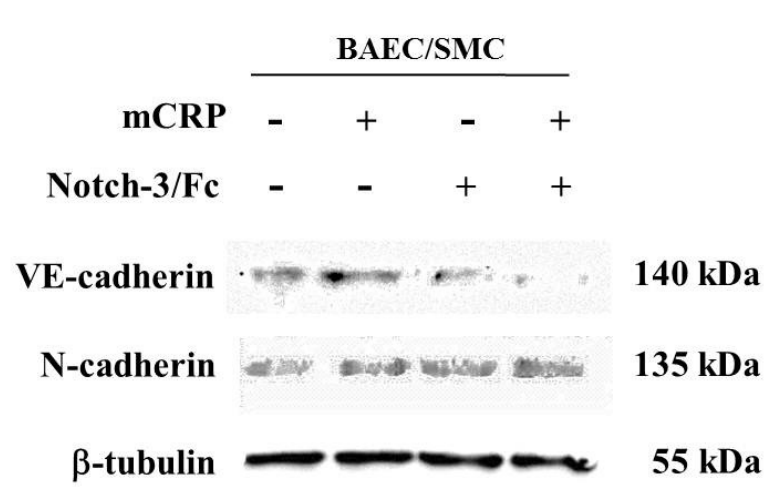

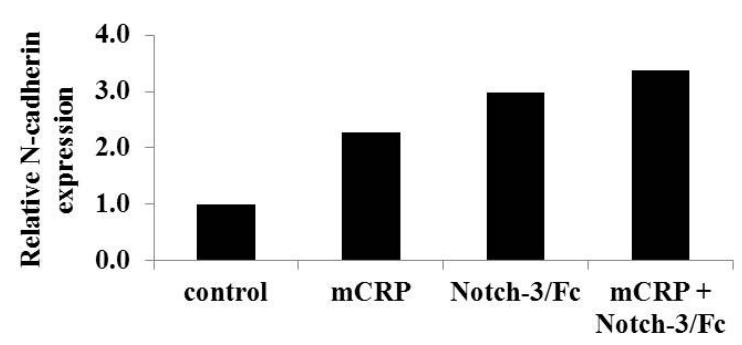

Figure 6 


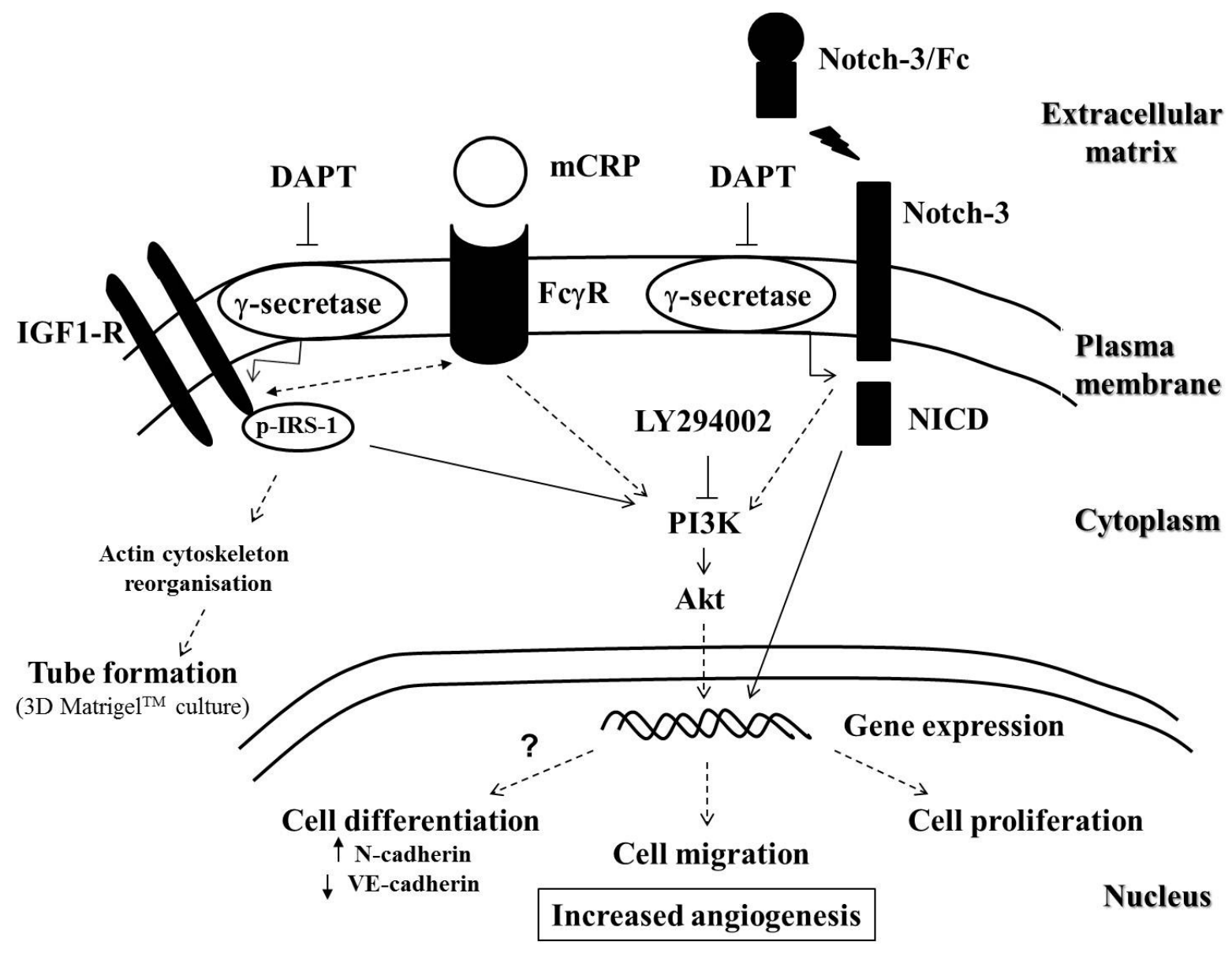

Figure 7 